Article

\title{
Energy Optimization Strategies for Eco-Friendly Cellular Base Stations
}

\author{
Mohammed H. Alsharif * (D), Jeong Kim and Jin Hong Kim \\ Department of Electrical Engineering, College of Electronics and Information Engineering, Sejong University, \\ 209 Neungdong-ro, Gwangjin-gu, Seoul 05006, Korea; kimjeong@sejong.ac.kr (J.K.); \\ veryoldboy7@naver.com (J.H.K.) \\ * Correspondence: malsharif@sejong.ac.kr; Tel.: +82-2-6935-2650; Fax: +82-2-3408-4329
}

Received: 14 May 2018; Accepted: 6 June 2018; Published: 8 June 2018

\begin{abstract}
This study focuses on the economic and environmental impacts of the deployment of cellular base stations (BSs) in remote/rural areas of South Korea. The optimal system, energy production, and operational costs of various renewable energy systems (RESs), such as solar power systems and hybrid solar power/wind power systems, in supplying third-generation cellular BSs with their required energy are discussed in this paper. To highlight the economic feasibility of the proposed RESs, a comparison between their economic feasibilities is presented. In addition, a comparison between the economic feasibilities of the proposed RESs and the classic energy solution of using a diesel generator (DG) is provided. Results show that the total operating expenses that can be saved can reach up to $56.13 \%$ if DG is replaced with the hybrid solar power/wind power system. Moreover, the operating expense savings are increased to $56.99 \%$ when a stand-alone solar power system is used. These results can be considered a valuable reference for mobile operators to show that shifting toward renewable energy technology is an attractive option.
\end{abstract}

Keywords: cellular networks; renewable energy; green energy; eco-friendly energy; energy optimization; economic feasibility; operating expenses

\section{Introduction}

Cellular networks have witnessed a significant development in the last decade. However, apart from the environmental impact of off-grid, diesel generator (DG)-powered mobile base stations (BSs) deployed in remote areas, the operating expenses (OPEX) for the intensive deployment of cellular BSs in urban and rural areas to provide mobile services to the largest number of subscribers are major concerns of mobile operators [1]. These concerns exert considerable pressure on mobile operators to meet the demands of environmental conservation and OPEX reduction because the high energy consumption of mobile networks has resulted in a significant increase in the number of mobile BSs, which are considered the most energy-consuming element in a mobile network [2]. In modern societies and industrialized countries, access to secure, sustainable, and affordable energy is a key factor for sustainable development and prosperity at the economic, social, and environmental levels [3]. At present, technological advances in green energy (renewable energy) can be harnessed to achieve the vision of mobile operators in expanding the coverage of cellular networks while maintaining profitability and reducing environmental impacts [4].

South Korea is located between $33^{\circ}$ and $39^{\circ} \mathrm{N}$ latitude and between $124^{\circ}$ and $130^{\circ} \mathrm{E}$ longitude with an average solar radiation between $5.48 \mathrm{kWh} / \mathrm{m}^{2} /$ day in May and $2.56 \mathrm{kWh} / \mathrm{m}^{2} /$ day in December [5]. Meanwhile, the country's average wind speed, which is between $4.62 \mathrm{~m} / \mathrm{s}$ in February and $3.45 \mathrm{~m} / \mathrm{s}$ in September, is considered low [6]. However, wind generators are used in hybrid systems integrated with solar panels to ensure reliability [7]. Accordingly, this study examines the feasibility of two 
options for renewable energy systems (RESs), namely, (1) a stand-alone photovoltaic (PV) system and (2) a hybrid PV/wind turbine (WT) system, to feed a Universal Mobile Telecommunications System (UMTS), known as the "third generation (3G)" of mobile communication, off-grid BS site (UMTS-BS). The main contributions of this study are:

(a) to determine the optimum size of and the technical criteria for a solar power system and a hybrid solar power/wind power system, and thus, ensure the full energy autonomy of a UMTS-BS under various daily solar radiation conditions in South Korea

(b) to analyze and evaluate the feasibility of using a solar power system and a hybrid solar power/wind power system in terms of energy yield, to ensure $100 \%$ energy autonomy and sustainability, and economic yield, to ensure cost-effectiveness

(c) to analyze and compare the consequences of selecting between the proposed RESs and the classic energy solution of using DGs on reducing OPEX and mitigating greenhouse gas (GHG) emissions

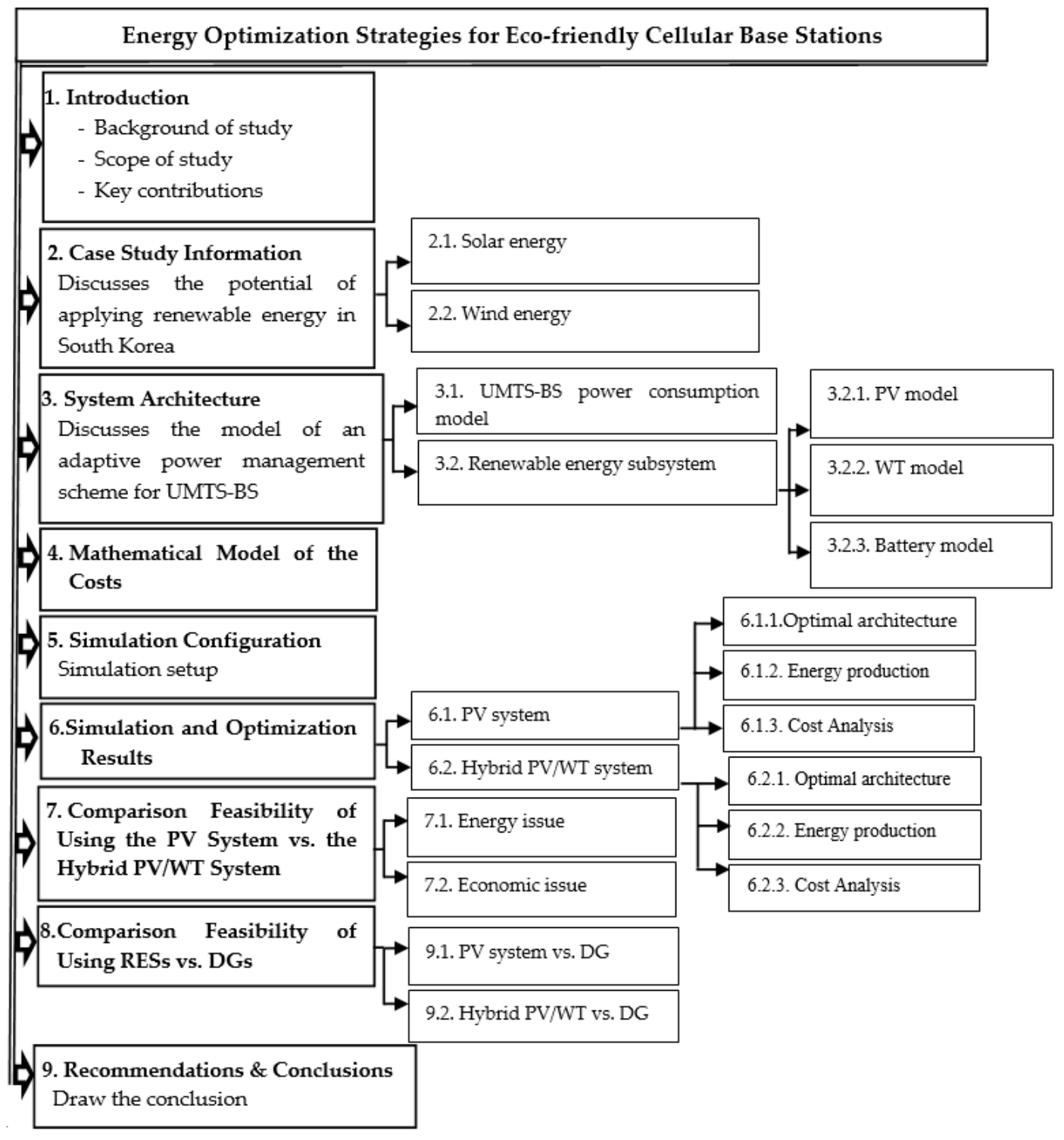

Figure 1. Schematic of the structure of the study. 
The remainder of this paper is organized as follows. Section 2 provides an overview of the study area considered in this research. Section 3 discusses the components and modeling of the proposed systems. The mathematical model of cost is described in Section 4. Section 5 presents a simulation setup considered in HOMER software and a system layout in HOMER. The simulation and optimization results are discussed in Section 6. A comparison among various RESs (e.g., solar power system and hybrid solar power/wind power system) in terms of energy and economic issues is provided in Section 7. Meanwhile, a comparison between RESs and the traditional energy source (DG) is provided in Section 8. Section 9 draws the conclusion of the study. The outline of the paper is presented in Figure 1.

\section{Case Study Information}

South Korea exhibits considerable potential for using renewable energy resources. However, these resources have not been applied extensively in the telecommunication sector, and research and development in this area are ongoing. The potential for utilizing solar and wind energies in South Korea is investigated in the following subsections.

\subsection{Solar Energy}

South Korea is located between $33^{\circ}$ and $39^{\circ} \mathrm{N}$ latitude and between $124^{\circ}$ and $130^{\circ} \mathrm{E}$ longitude, with an average solar radiation of $4.01 \mathrm{kWh} / \mathrm{m}^{2} /$ day and 0.503 clearness index; the maximum solar radiation is $5.48 \mathrm{kWh} / \mathrm{m}^{2} /$ day in May and the minimum is $2.56 \mathrm{kWh} / \mathrm{m}^{2} /$ day in December [8]. Figure 2 shows the average daily solar radiation per month. The long rainy period in early summer decreases global horizontal irradiance in June and July.

However, the average daily solar radiation varies from one province to another. Figure 3 shows the average daily solar radiation in various provinces of South Korea. The map of the average daily solar radiation (Figure 3) indicates a high average daily solar radiation of over $5 \mathrm{kWh} / \mathrm{m}^{2}$ in Jeju Island and the southeastern coastal area. By contrast, the monthly average daily solar radiation is lower $\left(4.7 \mathrm{kWh} / \mathrm{m}^{2}\right)$ in the northwestern region around Seoul. In addition, Gochang presents the lowest monthly average daily solar radiation of $4.48 \mathrm{kWh} / \mathrm{m}^{2}$.

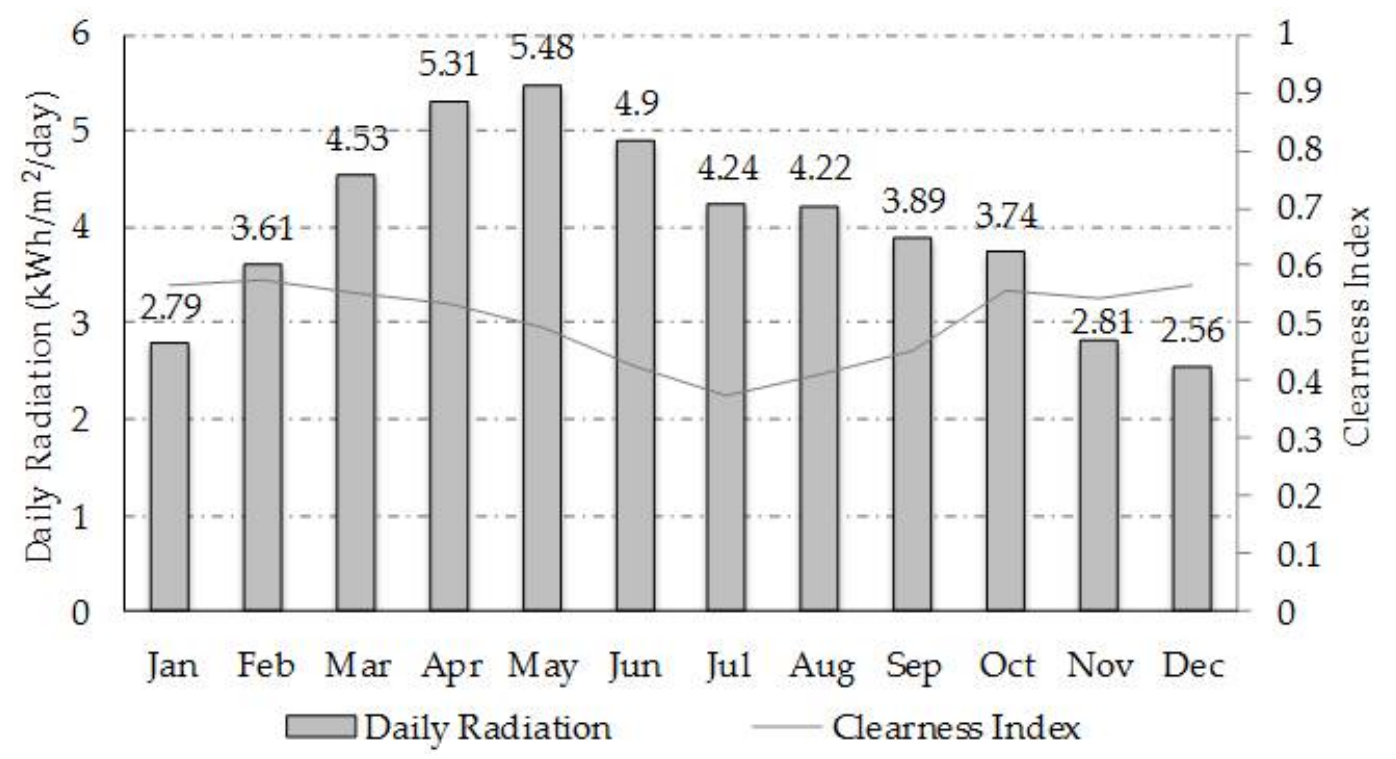

Figure 2. Average daily solar radiation per month [8]. 


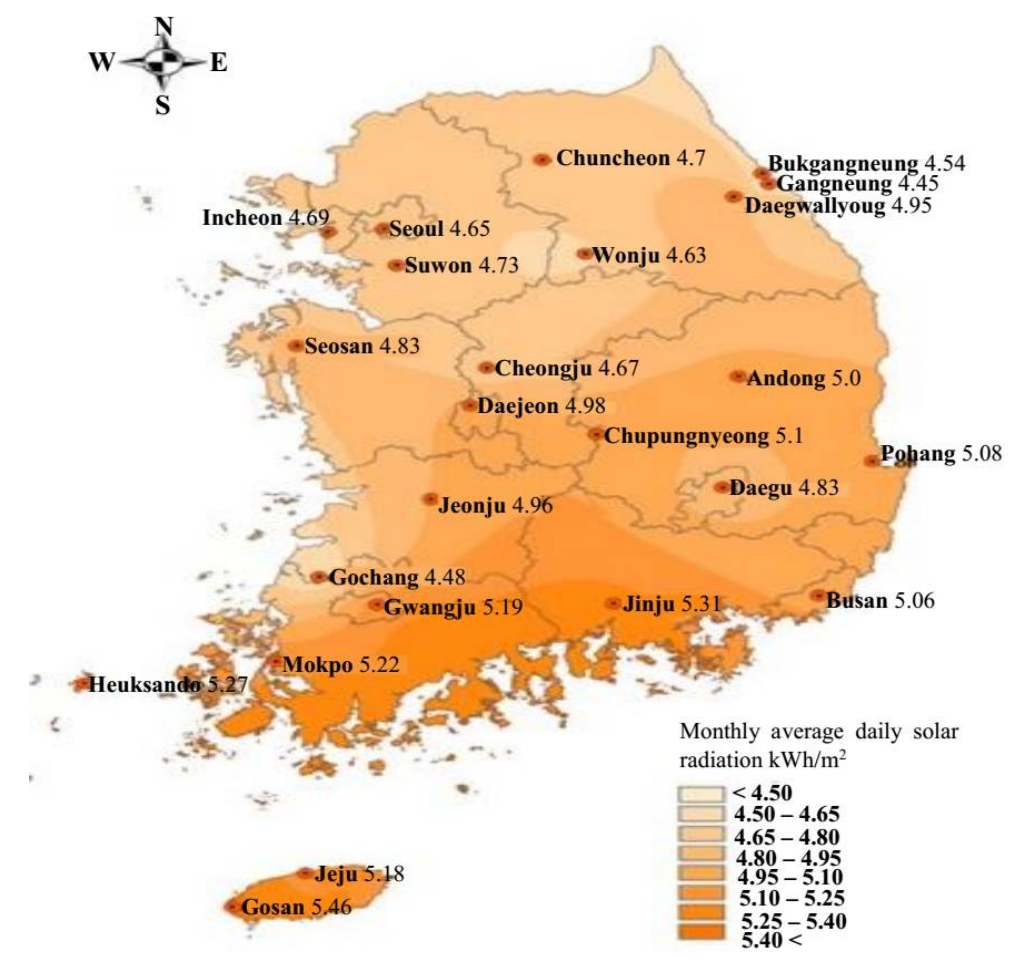

Figure 3. Average daily solar radiation in various provinces of South Korea [9].

\subsection{Wind Energy}

Figure 4 shows that the average wind speed in South Korea, i.e., $4.0 \mathrm{~m} / \mathrm{s}$, varies from $3.45 \mathrm{~m} / \mathrm{s}$ in September to $4.62 \mathrm{~m} / \mathrm{s}$ in February [10]. The average wind speed is classified as low; however, the wind can generate a high amount of energy in winter, particularly in the eastern and southeastern coasts; during strong surges of cold air, wind speed can reach up to $7.5 \mathrm{~m} / \mathrm{s}$ [11,12]. In summer, wind speed evidently and considerably decreases compared with that in winter. This seasonal variation in wind speed is highly related to atmospheric pressure and wind direction in South Korea. Figure 5 shows the wind direction in South Korea during winter. The main wind direction in winter is northwest in most areas. Meanwhile, the northeast wind appears in some parts of the southern west coast and southern coast of Gyeongnam. In addition, southwestern winds can be observed in Gangwon Province. The distribution of wind direction reflects the northwestern wind system due to the Siberian high pressure during winter in the northern part of Korea.

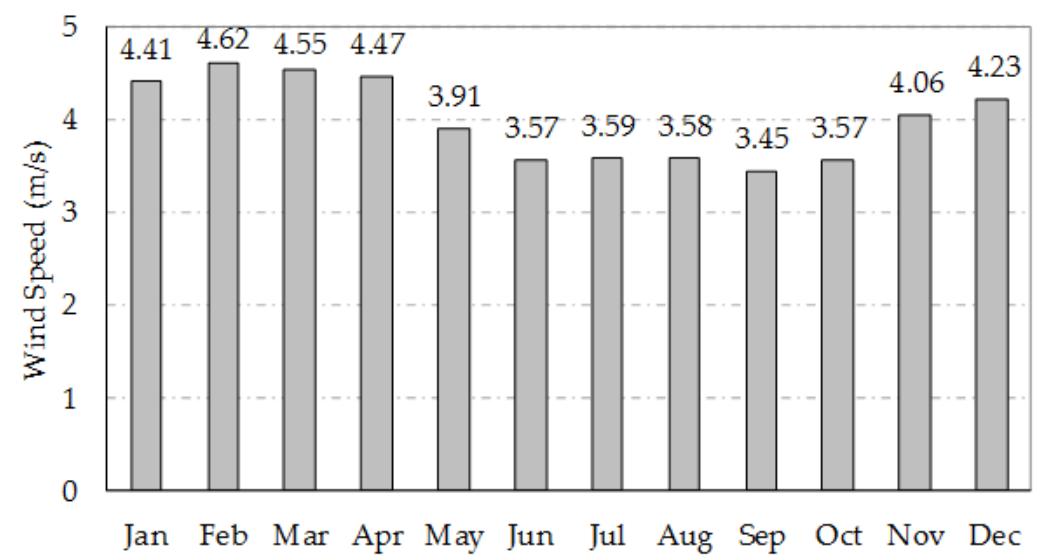

Figure 4. Average daily wind speed per month [6]. 


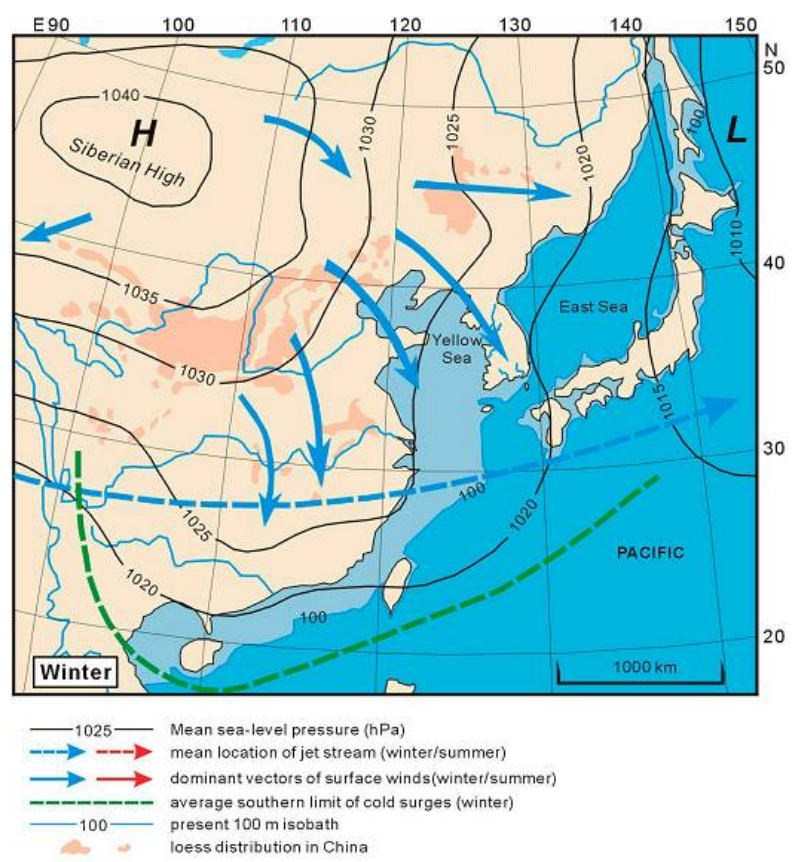

Figure 5. Average daily wind speed per month [12].

The average wind resource of South Korea is less than $5.0 \mathrm{~m} / \mathrm{s}$; hence, a stand-alone wind power system is unreasonable as a reliable or practical energy source [13]. However, wind generators are used in hybrid systems integrated with solar panels to ensure reliability. The selection of a suitable WT for low wind speed is a critical issue. A mobile BS tower structure can be appropriately modified to integrate WT into the tower itself, thereby saving space and installation cost.

\section{System Modeling}

The modeling of the RES scheme integrated with UMTS-BS is shown in Figure 6.

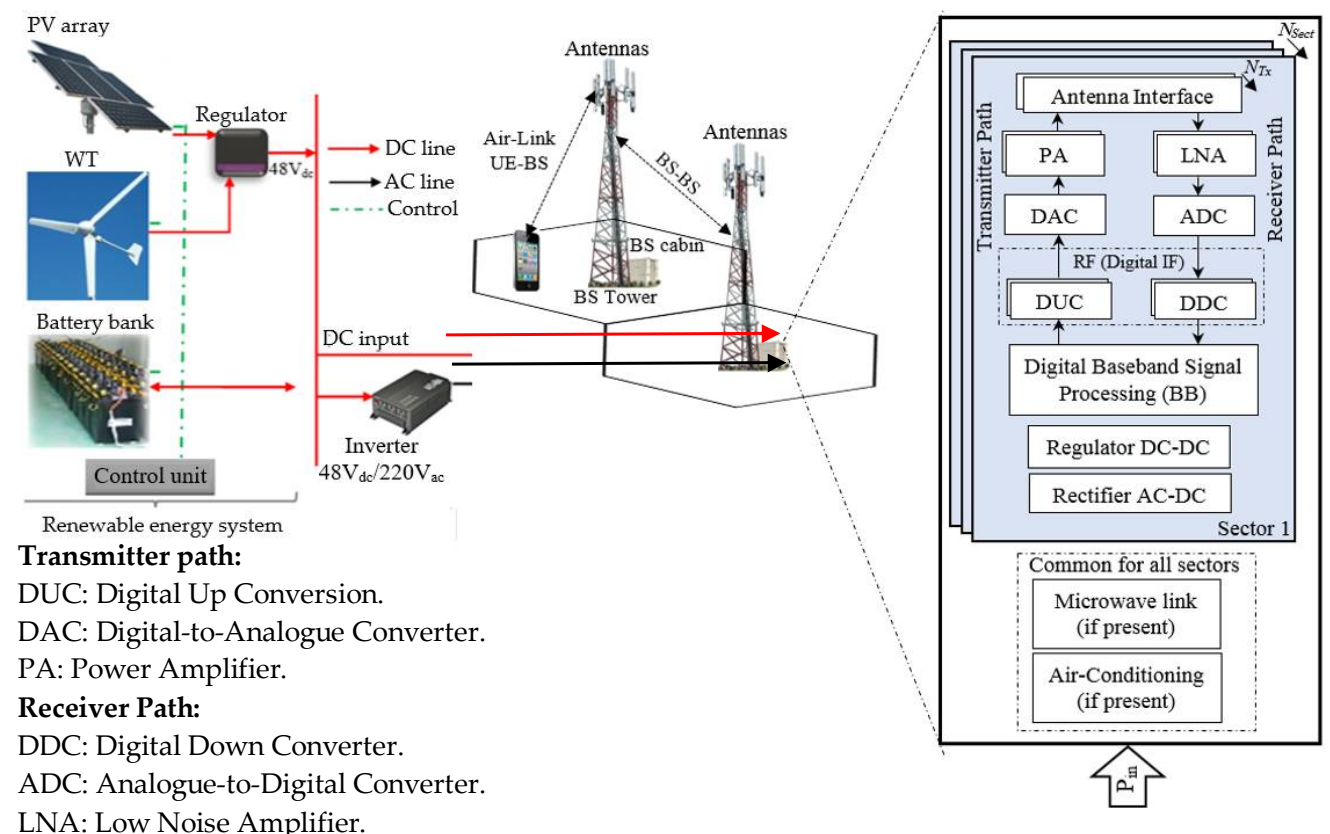

Figure 6. Sustainable UMTS-BS model in a smart grid environment. 


\subsection{Cellular Mobile BS Power Consumption Model}

UMTS-BS can be defined as a link that provides a direct path from a mobile core network to mobile stations that cover various cells. As shown in Figure 6, a BS is primarily a DC load that mainly consists of power amplifiers (PA), a radio-frequency transceiver (RF), a baseband unit (BB), a microwave backhaul, and auxiliary equipment (e.g., lighting and air-conditioning units); accordingly, a solar PV panel can directly power a BS $[14,15]$. The power consumption of each mobile cellular BS unit is provided in Table 1. The total power requirement of a site is calculated using [14]:

$$
P_{B S}=\frac{N_{T R X}\left(P_{P A}^{D C}+P_{R F}^{D C}+P_{B B}^{D C}\right)}{\left(1-\sigma_{D C}\right)\left(1-\sigma_{c o o l}\right)}+P_{m l}+P_{l}
$$

where $N_{T R X}$ is the total number of transceivers; $P_{P A}^{D C}$ is the power consumed by a PA at maximum load; $P_{B B}^{D C}$ is the power consumed by a BB unit; $P_{R F}^{D C}$ is the power consumed by RF; $\sigma_{D C}$ is a DC-DC loss factor; $\sigma_{\text {cool }}$ is a cooling loss factor; $P_{m l}$ is the power consumed by microwave backhaul; and $P_{l}$ is the power consumed by auxiliary equipment (e.g., lighting), which operates between 7 p.m. and 7 a.m.

Table 1. Power consumption of cellular UMTS-BS.

\begin{tabular}{|c|c|c|c|}
\hline Item & Notation & Unit & UMTS-BS \\
\hline \multirow{3}{*}{ Power amplifier } & $\begin{array}{c}\text { Max transmit }(r m s) \text { power, } \\
P_{\max }\end{array}$ & W & 40 \\
\hline & PA efficiency, $\mu$ & $\%$ & 45 \\
\hline & $P_{P A}^{D C}=P_{\max } / \mu$ & W & 89 \\
\hline \multirow{3}{*}{ Radio frequency } & $P_{T X}$ & $\mathrm{~W}$ & 5.7 \\
\hline & $P_{R X}$ & W & 5.2 \\
\hline & $P_{R F}^{D C}$ & $\mathrm{~W}$ & 10.9 \\
\hline \multirow{4}{*}{ Baseband } & Radio (inner $R x / T x$ ) & W & 5.4 \\
\hline & Turbo code (outer $R x / T x$ ) & $\mathrm{W}$ & 4.4 \\
\hline & Processor & $\mathrm{W}$ & 5.0 \\
\hline & $P_{B B}^{D C}$ & $\mathrm{~W}$ & 73.5 \\
\hline \multicolumn{2}{|c|}{ DC-DC loss, $\sigma_{D C}$} & $\%$ & 6.0 \\
\hline \multicolumn{2}{|c|}{ Cooling loss, $\sigma_{\text {cool }}$} & $\%$ & 10.0 \\
\hline \multicolumn{2}{|c|}{ Total per TRX $=\frac{P_{P A}^{D C}+P_{R F}^{D C}+P_{B B}^{D C}}{\left(1-\sigma_{D C}\right)\left(1-\sigma_{c o o l}\right)}$} & $\mathrm{W}$ & 204.97 \\
\hline \multicolumn{2}{|c|}{ Number of sectors $\left(N_{S e c t}\right)$} & \# & 3 \\
\hline \multicolumn{2}{|c|}{ Number of antennas $\left(N_{A n t}\right)$} & \# & 2 \\
\hline \multirow{3}{*}{\multicolumn{2}{|c|}{$\begin{array}{c}\text { Number of transceivers }\left(\mathrm{N}_{\mathrm{TRX}}=N_{\text {Sect }} \times N_{\text {Ant }} \times N_{\text {Carr }}\right) \\
\text { Total number of } \mathrm{N}_{\mathrm{TRX}} \text { chains, } \mathbf{P}_{\mathbf{o p}}=\mathbf{N}_{\mathrm{TRX}} \times \text { Total per TRX } \\
\text { Microwave link }\left(P_{\text {1 }}\right)\end{array}$}} & \# & 6 \\
\hline & & $\mathrm{W}$ & 1230 \\
\hline & & $\mathrm{W}$ & 80 \\
\hline \multicolumn{2}{|c|}{ Lamps $\left(P_{l}\right)$} & $\mathrm{W}$ & 40 \\
\hline
\end{tabular}

\subsection{Hybrid RES}

The following subsections highlight the major components of the proposed RESs and their mathematical models.

\subsubsection{PV Model}

The daily energy output $(E)$ of a PV system is directly proportional to the total solar panel area or PV array area $(A)$, solar panel efficiency $(r)$, daily average solar radiation $(H)$, and performance ratio (PR). $E$ increases when $A$ is large. Meanwhile, the $A$ of a solar power system is limited. Thus, solar radiation is the factor that can increase $E$ at a limited $A$, i.e., the output energy of a solar power system increases with increasing solar radiation at constant $A$. However, PV panels exhibit relatively low efficiency at $4-12 \%$ for thin film panels and below $22 \%$ for crystalline panels $[16,17]$, which affects the production of energy regardless of the availability of solar radiation. In addition, 
dust significantly influences the performance of PV, thereby causing further reduction in overall efficiency. Accordingly, the $E$ of a PV system can be calculated using the following formula $[8,18,19]$ :

$$
E_{P V}=Y_{P V} \times P S H \times f_{P V},
$$

where $Y_{P V}$ is the peak capacity of a PV array measured in $\mathrm{kW}$. The average daily solar radiation is the peak solar hour (PSH), which is measured per hour. Loss factors due to dust and temperature, and wire losses that can affect the wattage output of a solar PV are expressed as the PV derating factor $f_{P V}$, where the coefficient of losses ranges from 0.5 to 0.9 with a default value of 0.75 .

\subsubsection{WT Model}

The sizes of rotor blades, wind velocity, and air density are considered the main parameters for determining the output power of a WT, which can be expressed using the following mathematical model $[7,20,21]$ :

$$
P=\frac{1}{2} \rho A V^{3} C_{p}
$$

where wind speed $(\mathrm{m} / \mathrm{s})$ is represented by $V$. The coefficient by Betz limit is represented by $C p . A$ is the swept area $\left(\pi D^{2} / 4, D\right.$ is the rotor diameter in $\mathrm{m}^{2}$ and $\left.\pi=3.1416\right)$. The corrected monthly air density $\left(\mathrm{kg} / \mathrm{m}^{3}\right)$ is represented by $\rho$, which can be estimated using the following equation $[7,20,21]$ :

$$
\rho=\frac{P}{R T}
$$

where $P$ is the monthly mean air pressure $\left(\mathrm{N} / \mathrm{m}^{2}\right), T$ is the monthly mean air temperature $(\mathrm{K})$, and $R$ is the specific gas constant for air $(287 \mathrm{~J} / \mathrm{kg} \mathrm{K})$.

Equation (3) can be simplified to $K \cdot V^{3}$ considering that rotor area and air density are fixed and represented by $K$. Thus, the output power of a WT depends only on wind speed, which is represented by $V^{3}$. Therefore, the available wind energy is proportional to the cube of wind speed or wind velocity.

\subsubsection{Battery System Model}

In a hybrid system, the mathematical modeling of a battery system generally depends on the state of charge (SOC) and depth of discharge (DOD) of the battery. SOC denotes the cumulative sum of the daily charge or discharge transfers of a battery. Meanwhile, DOD is calculated as the percentage of energy that can be withdrawn from a battery; it can be expressed as follows [22]:

$$
D O D=1-S O C_{m i n} .
$$

In addition, HOMER is used to calculate the number of days that a fully charged battery can autonomously supply a fully loaded BS before the battery runs out of power based on the following equation [22]:

$$
A_{\text {batt }}=\frac{N_{\text {batt }} \times V_{\text {nom }} \times Q_{\text {nom }}\left(1-\frac{S O C_{\min }}{100}\right)(24 \mathrm{~h} / \mathrm{d})}{L_{\text {prim-avg }}(1000 \mathrm{Wh} / \mathrm{kWh})}
$$

where $N_{\text {batt }}$ denotes the total number of batteries within a battery pack. The nominal voltage of a single battery is represented by $V_{\text {nom }}$. The nominal capacity of an individual battery within a battery pack is represented by $Q_{n o m}$. The daily average load of a BS is represented by $L_{\text {prim-avg. }}$.

Furthermore, the overall lifetime of a battery can be expressed as [22]:

$$
R_{\text {batt }}=\min \left(\frac{N_{\text {batt }} \times Q_{\text {lifetime }}}{Q_{\text {thrpt }}}, R_{\text {batt }, f}\right)
$$


where $Q_{\text {lifetime }}$ represents the lifetime throughput of a single battery measured in $\mathrm{kWh}$. The annual battery throughput measured in $\mathrm{kWh} /$ year is represented by $Q_{\text {thrpt }}$. The battery float life (year) is represented by $R_{\text {batt } f \text {. }}$.

\section{Modeling of Costs}

In HOMER, the total net present cost (NPC) of a system is the present value of all the costs that the system has incurred over its lifetime. NPC includes capital costs, replacement costs, operation and management $(\mathrm{O} \& \mathrm{M})$ costs, fuel costs, emission penalties, and the costs of buying power from the grid. Thus, NPC can be mathematically expressed as follows [22]:

$$
N P C=\frac{T C}{C F}
$$

The total annualized cost (TC), which is the annualized value of the total NPC and the capital recovery factor $(C F)$, is expressed as follows [22]:

$$
C F=\frac{i(1+i)^{n}}{(1+i)^{n}-1}
$$

where $i$ is the annual real interest rate, and $n$ is the project lifetime.

The discount factor $f_{d}$ is used to calculate the present value of a cash flow that occurs in any year during a project's lifetime. $f_{d}$ can be mathematically expressed as [22]:

$$
f_{d}=\frac{1}{(1+i)^{n}}
$$

The salvage value $S$ is the power system component value that remains at the completion of a particular project's lifetime. HOMER calculates salvage cost using the following equation [22]:

$$
S=\operatorname{rep}\left(\frac{\operatorname{rem}}{\operatorname{comp}}\right)
$$

where the replacement cost of the component is represented by rep, the remaining lifetime of the component is represented by rem, and the lifetime of the component is represented by comp.

\section{System Implementation and Configuration}

This section highlights the architecture layout of the proposed RESs and the parameters of the components used in this simulation. Table 2 summarizes the parameters of the components used in HOMER software. The average daily BS load consumption profile is depicted in Figure 7. In addition, the characteristics of the "Trojan L16P" battery model that are considered in this study are presented in Figure 8. Moreover, the layout of the RES models in HOMER that are considered in this study is shown in Figure 9.

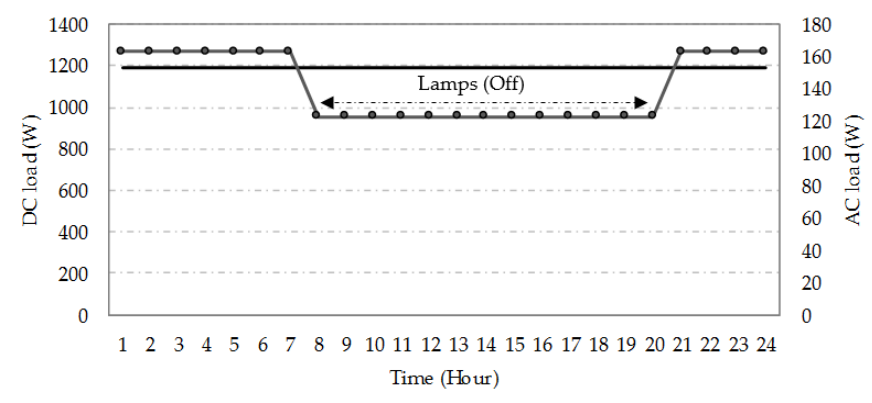

Figure 7. Hourly load profile of UMTS-BS. 


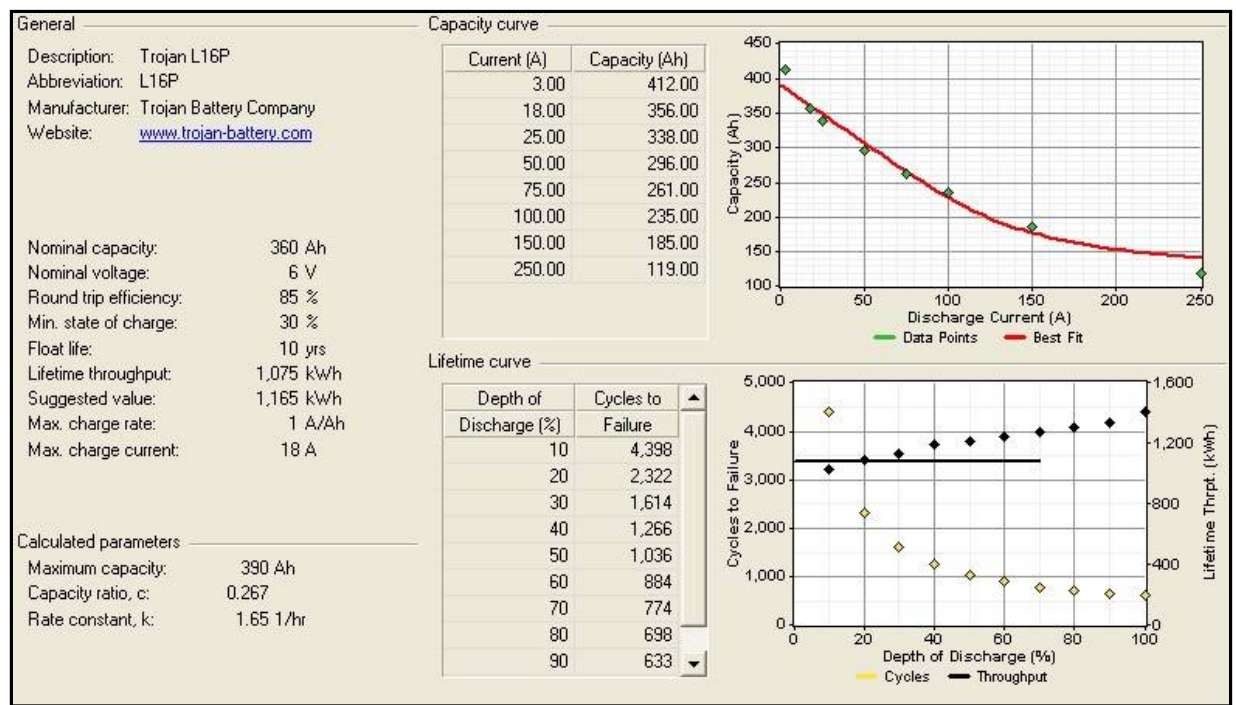

Figure 8. Characteristics of "Trojan L16P" battery model.
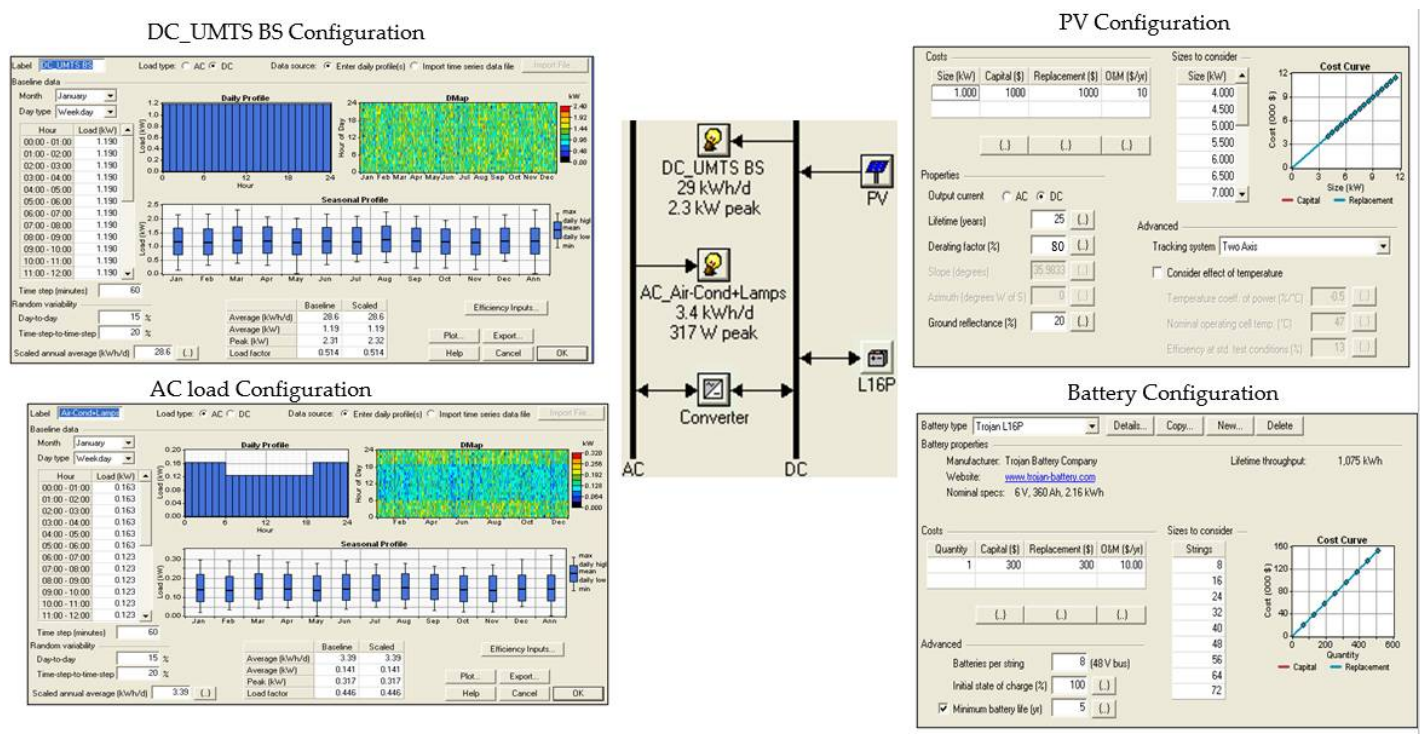

(a)

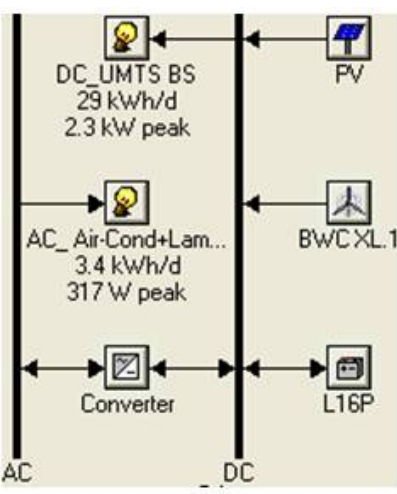

WT Configuration

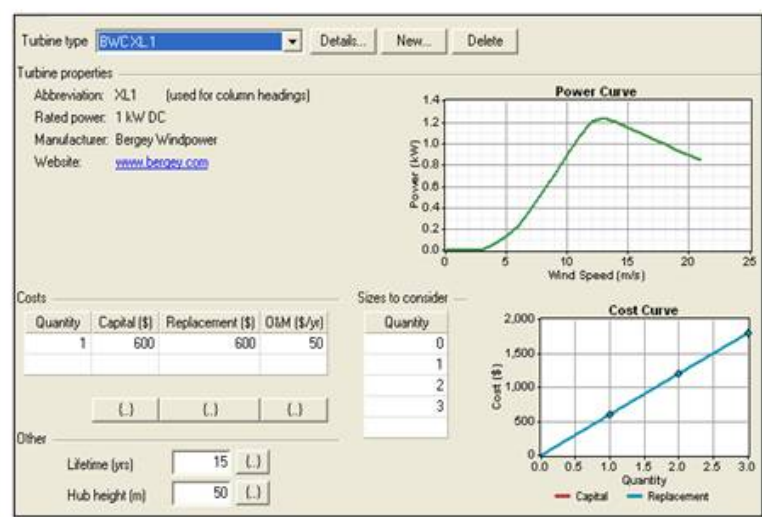

(b)

Figure 9. Layout of RESs in HOMER. (a) PV system; (b) Hybrid PV/WT system. 
Table 2. Configuration of HOMER software.

\begin{tabular}{|c|c|c|}
\hline System & Parameters & Value \\
\hline Renewable energy resources & $\begin{array}{l}\text { Solar radiation } \\
\text { Wind speed }\end{array}$ & $\begin{array}{c}4.0,4.5,5.0,5.5 \mathrm{kWh} / \mathrm{m}^{2} / \text { day } \\
4.0 \mathrm{~m} / \mathrm{s}\end{array}$ \\
\hline Control parameters & $\begin{array}{l}\text { Annual real interest rate } \\
\text { Project lifetime }\end{array}$ & $\begin{array}{c}1.25 \% \\
10 \text { years }\end{array}$ \\
\hline PV & $\begin{array}{c}\text { Sizes considered } \\
\text { Operational lifetime } \\
\text { Efficiency } \\
\text { System tracking } \\
\text { Capital cost } \\
\text { Replacement cost } \\
\text { O\&M cost per year }\end{array}$ & $\begin{array}{c}4,4.5,5,5.5,6,6.5,7 \mathrm{~kW} \\
25 \text { years } \\
80 \% \\
\text { Two axes } \\
\$ 1 / \mathrm{W} \\
\$ 1 / \mathrm{W} \\
\$ 0.01 / \mathrm{W}\end{array}$ \\
\hline WT & $\begin{array}{c}\text { Sizes considered } \\
\text { Operational lifetime } \\
\text { Hub } \\
\text { Capital cost } \\
\text { Replacement cost } \\
\text { O\&M cost per year }\end{array}$ & $\begin{array}{c}1,2 \text {, and } 3 \mathrm{~kW} \\
15 \text { years } \\
50 \mathrm{~m} \\
\$ 0.6 / \mathrm{W} \\
\$ 0.6 / \mathrm{W} \\
\$ 0.05 / \mathrm{W}\end{array}$ \\
\hline Inverter & $\begin{array}{l}\text { Sizes considered } \\
\text { Efficiency } \\
\text { Operational lifetime } \\
\text { Capital cost } \\
\text { Replacement cost } \\
\text { O\&M cost per year }\end{array}$ & $\begin{array}{c}0.1,0.15,0.2,0.25, \& 0.3 \mathrm{~kW} \\
95 \% \\
15 \text { years } \\
\$ 0.4 / \mathrm{W} \\
\$ 0.4 / \mathrm{W} \\
\$ 0.01 / \mathrm{W}\end{array}$ \\
\hline Trojan L16P Battery & $\begin{array}{c}\text { Number of batteries } \\
\text { Round trip efficiency } \\
\text { Minimum state of charge } \\
\text { Nominal voltage } \\
\text { Nominal current } \\
\text { Nominal capacity } \\
\text { Min. operational lifetime } \\
\text { Capital cost } \\
\text { Replacement cost } \\
\text { O\&M cost per year }\end{array}$ & $\begin{array}{c}32,40,48,56,64,72 \\
85 \% \\
30 \% \\
6 \mathrm{~V} \\
360 \mathrm{Ah} \text { at } 20 \mathrm{~h} \\
6 \mathrm{~V} \times 360 \mathrm{Ah}=2.16 \mathrm{kWh} \\
5 \text { years } \\
\$ 300 \\
\$ 300 \\
\$ 10\end{array}$ \\
\hline
\end{tabular}

\section{Optimization and Simulation Results}

The system architecture, energy production, and cost analysis of the RESs are discussed in detail in the following subsections.

\subsection{PV System}

Different average values $\left(4.0,4.5,5.0\right.$, and $\left.5.5 \mathrm{kWh} / \mathrm{m}^{2}\right)$ of daily solar radiation are considered in the simulation because the average daily solar radiation varies from one province to another.

\subsubsection{Optimal System Architecture}

The economic criteria and sizes of the components of the proposed stand-alone PV system at different daily radiation values are summarized in Table 3.

The PV array is rated $9.0 \mathrm{~kW}$ at $4.0 \mathrm{kWh} / \mathrm{m}^{2} /$ day. The number of PV modules in series and parallel is achieved by dividing the designed system voltage by the nominal module voltage under the standard test condition. Thus, PV modules are connected as four in series and nine in parallel based on the Sharp ND-250QCs module. The nominal rated voltage of the Trojan L16P battery is 6 V; hence, a $48 \mathrm{~V}$ DC bus-bar connected in series was used. Accordingly, 64 units of battery operating at a nominal voltage of $6 \mathrm{~V}$ are connected 8 in series and 8 in parallel. 
Table 3. Economic criteria and sizes of the components of the proposed stand-alone PV system.

\begin{tabular}{|c|c|c|c|c|c|c|}
\hline \multicolumn{4}{|c|}{ Optimal Sizing } & \multicolumn{3}{|c|}{ Cost Factor } \\
\hline $\begin{array}{l}\text { Daily Radiation } \\
\left(\mathbf{k W h} / \mathrm{m}^{2}\right)\end{array}$ & PV (kW) & Battery (Unit) & Inverter (kW) & IC (\$) & Annual O\&M (\$) & NPC (\$) \\
\hline 4.0 & 9.0 & 64 & 0.3 & 28,320 & 733 & 30,366 \\
\hline 4.5 & 8.0 & 64 & 0.3 & 27,320 & 723 & 29,802 \\
\hline 5.0 & 7.5 & 64 & 0.3 & 26,820 & 718 & 29,521 \\
\hline 5.5 & 6.5 & 64 & 0.3 & 25,820 & 708 & 28,957 \\
\hline
\end{tabular}

\subsubsection{Energy Production (kWh/Year)}

Figure 10 summarizes the annual energy contribution of the PV system at different average values of daily solar radiation.

The average daily solar radiation of $4.0 \mathrm{kWh} / \mathrm{m}^{2}$ in South Korea is considered in the following analysis. The total annual energy production of the PV array is 10,538 $\mathrm{kWh}$, which was calculated using Equation (2). However, a dual-axis tracker system is used, which increases the total amount of energy to $14,938 \mathrm{kWh}$ /year. Meanwhile, $11,678 \mathrm{kWh} /$ year is the total annual energy required for the load (UMTS-BS). Thus, the total annual excess energy is $3.26 \mathrm{kWh}$. Furthermore, Figure 11 presents the monthly average electricity production of the PV array, which indicates that the maximum electricity production of the PV array is achieved in April and May, whereas the minimum is observed in July.

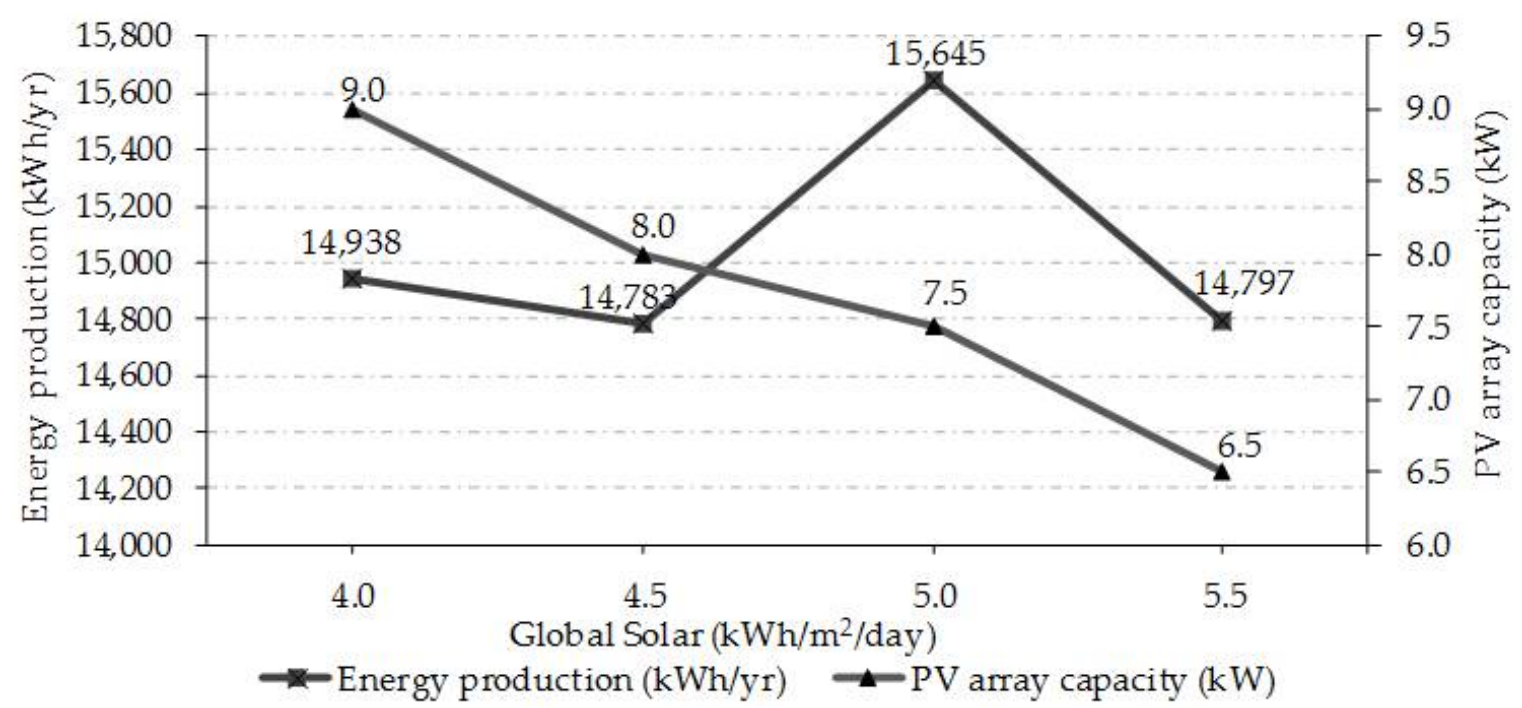

Figure 10. Annual energy contribution of the PV system at different average values of daily solar radiation.

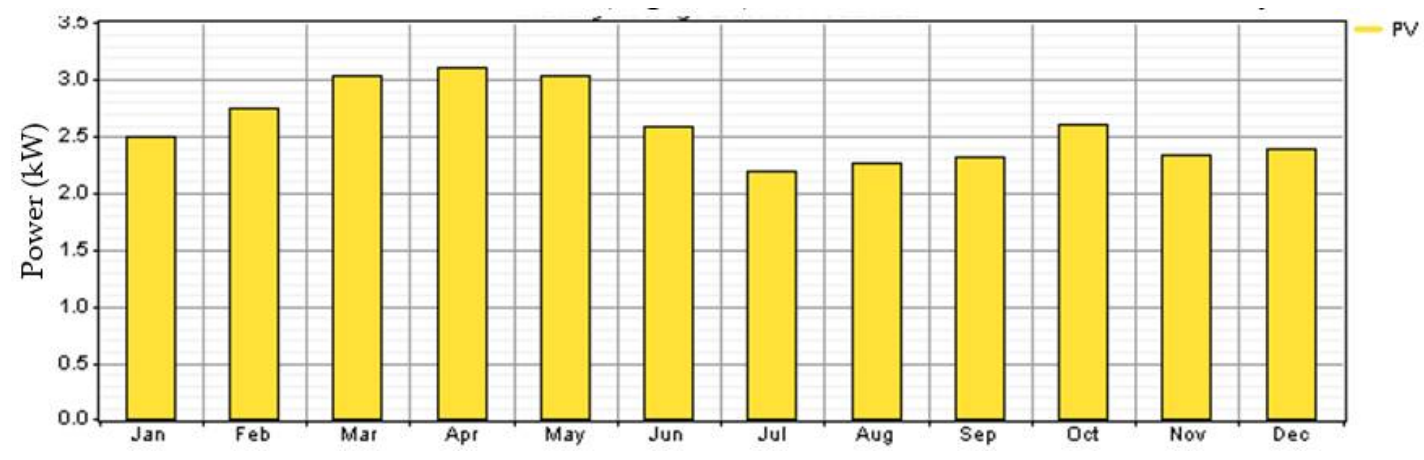

Figure 11. Monthly average electricity production of the PV array. 
The total annual input energy of the Trojan L16P battery is $7785 \mathrm{kWh}$, whereas its total annual output energy is $6649 \mathrm{kWh}$. Thus, the total annual energy loss of the Trojan L16P battery is $1136 \mathrm{kWh}$. Furthermore, batteries can autonomously supply the UMTS-BS load for $72.6 \mathrm{~h}$, which was calculated using Equation (6). The expected lifetime of a battery is 10 years, which was calculated using Equation (7). Figure 12 presents the monthly maximum and minimum SOCs of the Trojan L16P battery. The figure shows that the DOD of the Trojan L16P battery occurs at the end of July and the beginning of August. Additional details are provided in Figure 13, which shows a portion of the hourly simulation results of the energy content of the battery in a time series, in average hourly values of the PV array power output with SOC. The lowest level was reached on 4 August.

The total annual input energy of the inverter is $1301 \mathrm{kWh}$, whereas its total annual output energy is $1236 \mathrm{kWh}$. Thus, the total annual energy loss of the inverter is $65 \mathrm{kWh}$. Figure 14 presents the average monthly energy conversion of the inverter over 12 months.

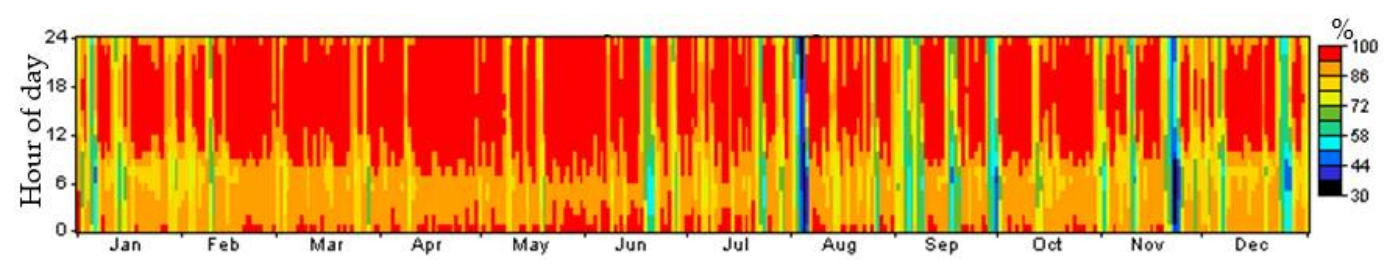

Figure 12. SOC of the battery in the PV system.

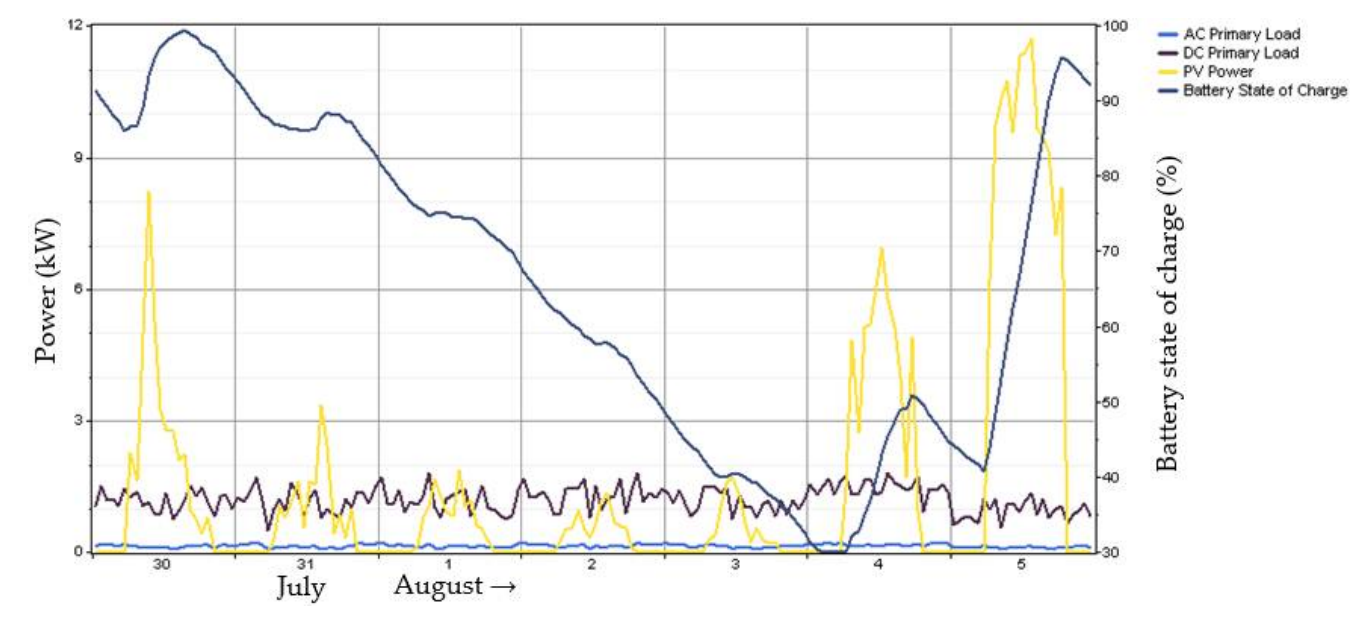

Figure 13. Hourly simulation results of the PV output power and energy stored in the battery bank.

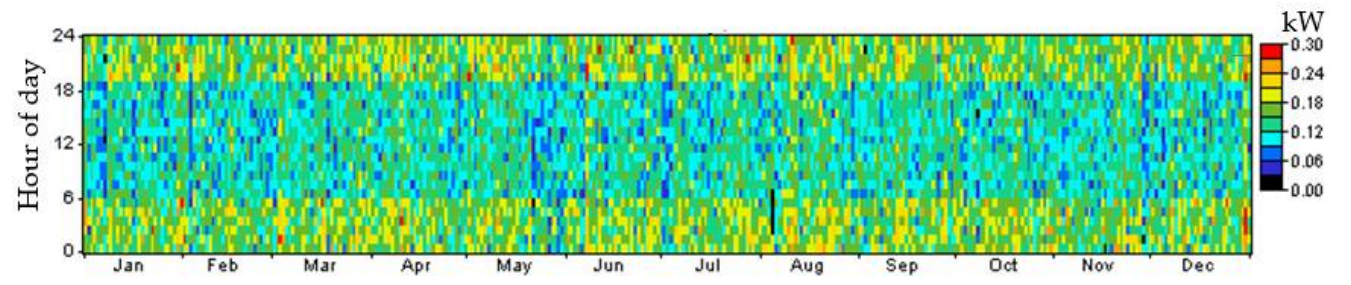

Figure 14. Inverter output power of the PV system.

\subsubsection{Costs}

The cash flow of the PV system over the project lifetime is summarized in Figure 15 based on a solar radiation of $4.0 \mathrm{kWh} / \mathrm{m}^{2} /$ day.

The PV system has an initial capital (IC) of $\$ 28,320$, annual O\&M cost of $\$ 733$, and salvage value of $\$ 544$, which were calculated using Equation (11). No replacement cost is necessary because project 
lifetime is 10 years, battery lifetime is estimated at 10 years, inverter lifetime is 15 years, and PV array lifetime is 25 years.

NPC is calculated by summing up the total discounts (as shown in Figure 16, which is computed using Equation (10)): capital cost of $\$ 28,320+$ O\&M cost of $\$ 6850$ - salvage value of $\$ 4804=\$ 30,366$. Figure 17 summarizes the total discounted costs for different proposed average values of daily solar radiation.

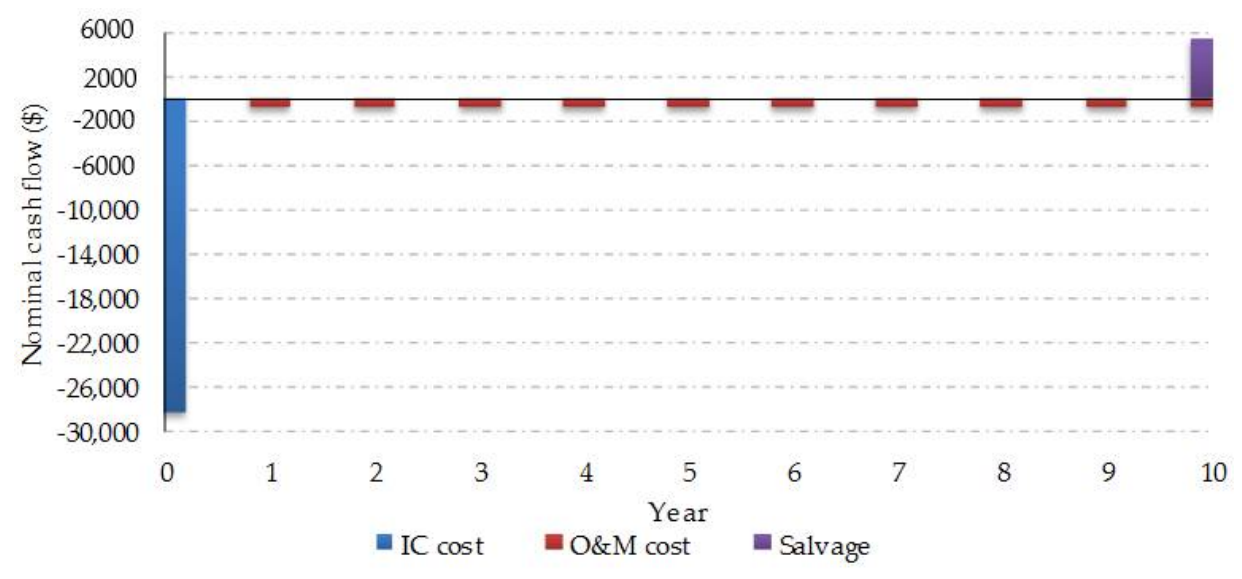

Figure 15. Summary of the cash flow of the PV system throughout the project lifetime.

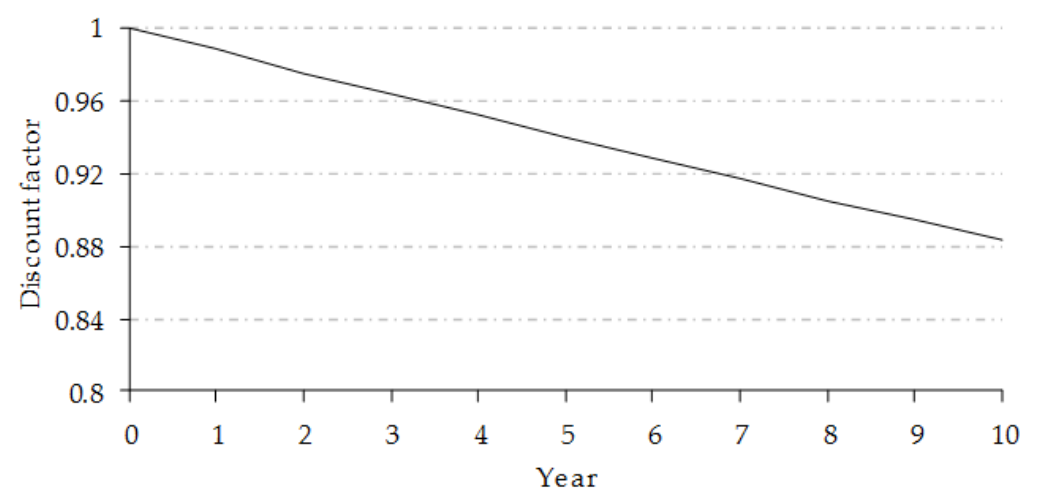

Figure 16. Discount factor for each year of the project lifetime.

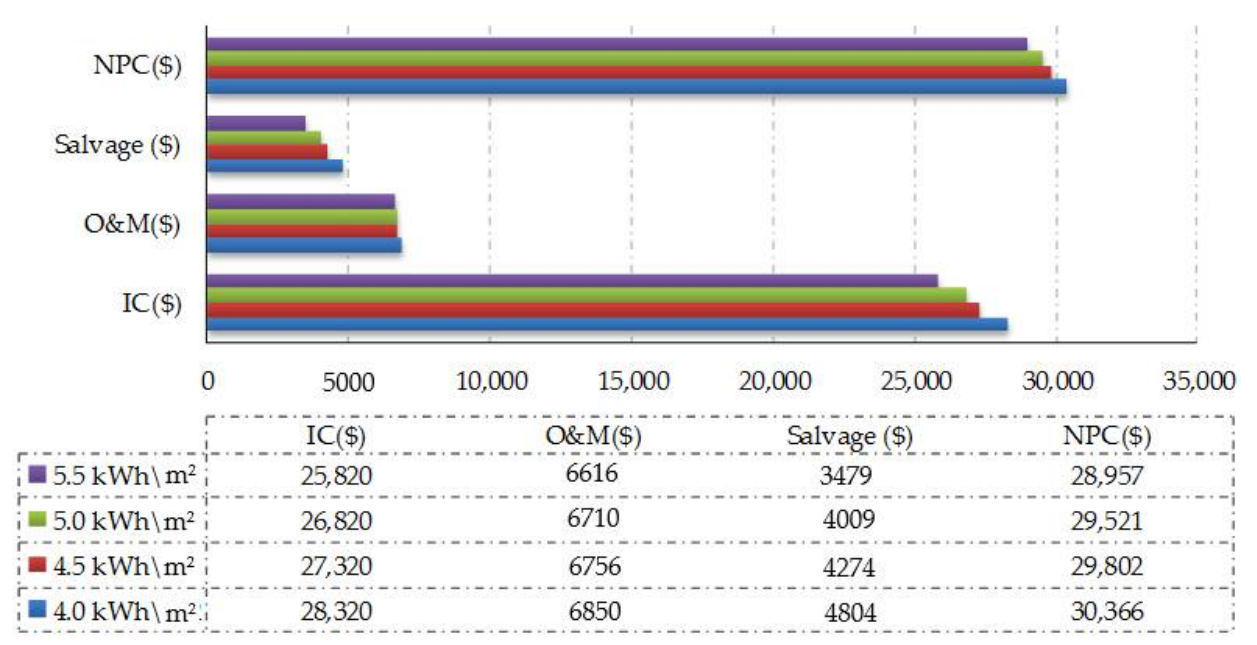

Figure 17. Total discounted costs over a period of the project lifetime for the PV system. 


\subsection{Hybrid PV/WT System}

\subsubsection{Optimal System Architecture}

The economic criteria and sizes of the components of the proposed hybrid PV/WT power system at different daily radiation values and a wind speed of $4.0 \mathrm{~m} / \mathrm{s}$ are summarized in Table 4 .

The PV capacity rating varies from $8.5 \mathrm{~kW}$ to $6.5 \mathrm{~kW}$ and corresponds to differences in solar radiation. PV capacity decreases as solar radiation increases. WT capacity is $1 \mathrm{~kW}$ for all cases because wind speed is constant at $4.0 \mathrm{~m} / \mathrm{s}$ in all cases. The optimal number of batteries is 64 , and the ideal inverter output is $0.3 \mathrm{~kW}$.

Table 4. Economic criteria and sizes of the components of the proposed hybrid PV/WT power system.

\begin{tabular}{|c|c|c|c|c|c|c|c|c|}
\hline \multicolumn{2}{|c|}{ Resources } & \multicolumn{4}{|c|}{ Optimum Sizing } & \multicolumn{3}{|c|}{ Cost Factor } \\
\hline $\begin{array}{c}\text { Wind } \\
\text { Speed }(\mathrm{m} / \mathrm{s})\end{array}$ & $\begin{array}{c}\text { Radiation } \\
\left(\mathbf{k W h} / \mathrm{m}^{2} / \mathrm{d}\right)\end{array}$ & PV (kW) & WT (kW) & $\begin{array}{l}\text { Battery } \\
\text { (Unit) }\end{array}$ & $\begin{array}{c}\text { Inverter } \\
(\mathbf{k W})\end{array}$ & IC (\$) & $\begin{array}{c}\text { Annual } \\
\text { O\&M (\$) }\end{array}$ & NPC (\$) \\
\hline \multirow{4}{*}{4.0} & 4.0 & 8.5 & 1 & 64 & 0.30 & 28,420 & 778 & 30,975 \\
\hline & 4.5 & 7.5 & 1 & 64 & 0.30 & 27,420 & 768 & 30,412 \\
\hline & 5.0 & 7.0 & 1 & 64 & 0.30 & 26,920 & 763 & 30,129 \\
\hline & 5.5 & 6.5 & 1 & 64 & 0.30 & 26,420 & 758 & 29.847 \\
\hline
\end{tabular}

\subsubsection{Energy Production (kWh/Year)}

Figure 18 summarizes the annual energy contribution of the hybrid PV/WT power system at different daily radiation values and a wind speed of $4.0 \mathrm{~m} / \mathrm{s}$.

The average daily solar radiation of $4.0 \mathrm{kWh} / \mathrm{m}^{2}$ and the average wind speed of $4.0 \mathrm{~m} / \mathrm{s}$ are considered in the following analysis. The total annual energy production of a PV array is $16,259 \mathrm{kWh}$, which represents $89 \%$ of the total annual energy production $(15,810 \mathrm{kWh})$ of the hybrid PV/WT system. Meanwhile, the total annual energy production of a WT is $1814 \mathrm{kWh}$, which represents $11 \%$ of the total annual energy production of the hybrid PV/WT system. WT initially provides output power at a wind speed of $4 \mathrm{~m} / \mathrm{s}$, as shown in Figure 19. Therefore, the total annual energy production of WT does not exceed $11 \%$ of the total annual energy production of the hybrid PV/WT system.

Figure 20 presents the monthly average electricity production of the hybrid PV/WT system. This figure indicates that the maximum electricity production of the hybrid PV/WT system occurred in April and May, whereas the minimum was observed in July. Furthermore, the maximum electricity production of WT was recorded in January and March, and the minimum was noted in September.

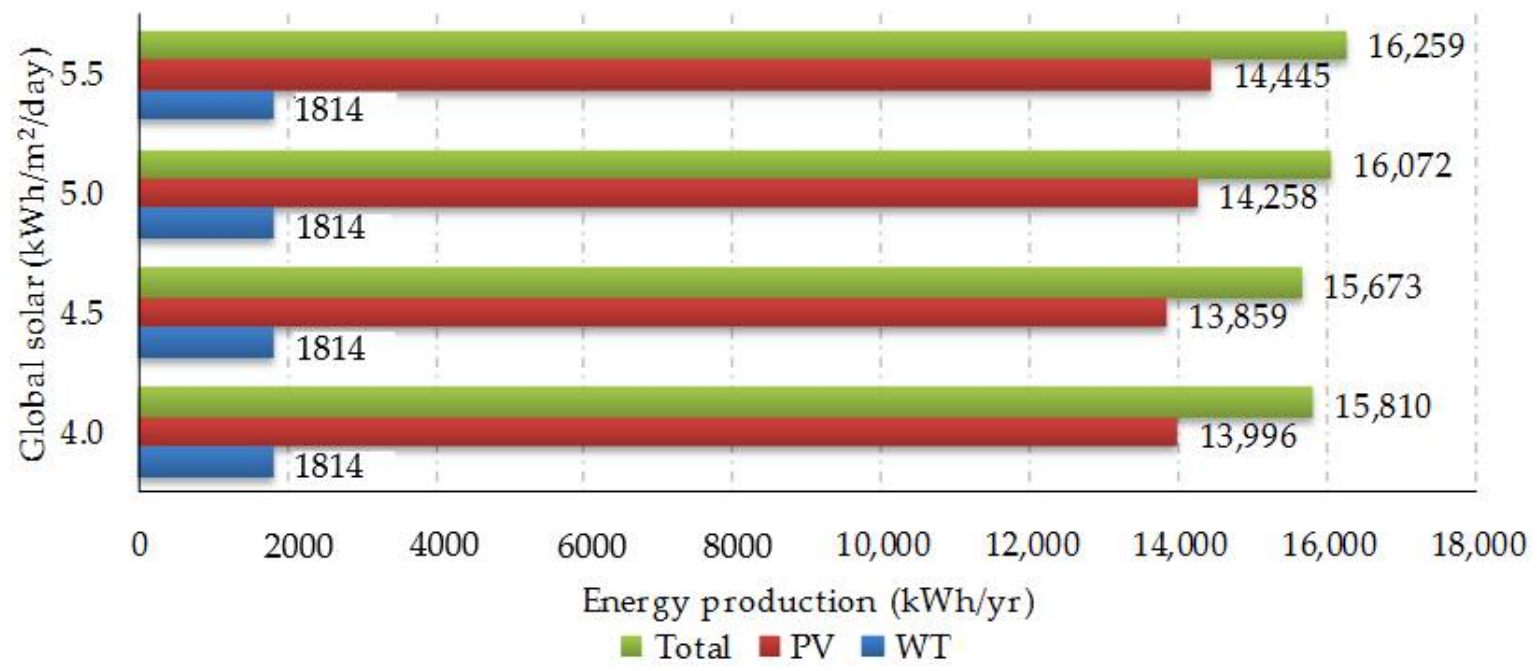

Figure 18. Annual energy production of different energy sources. 


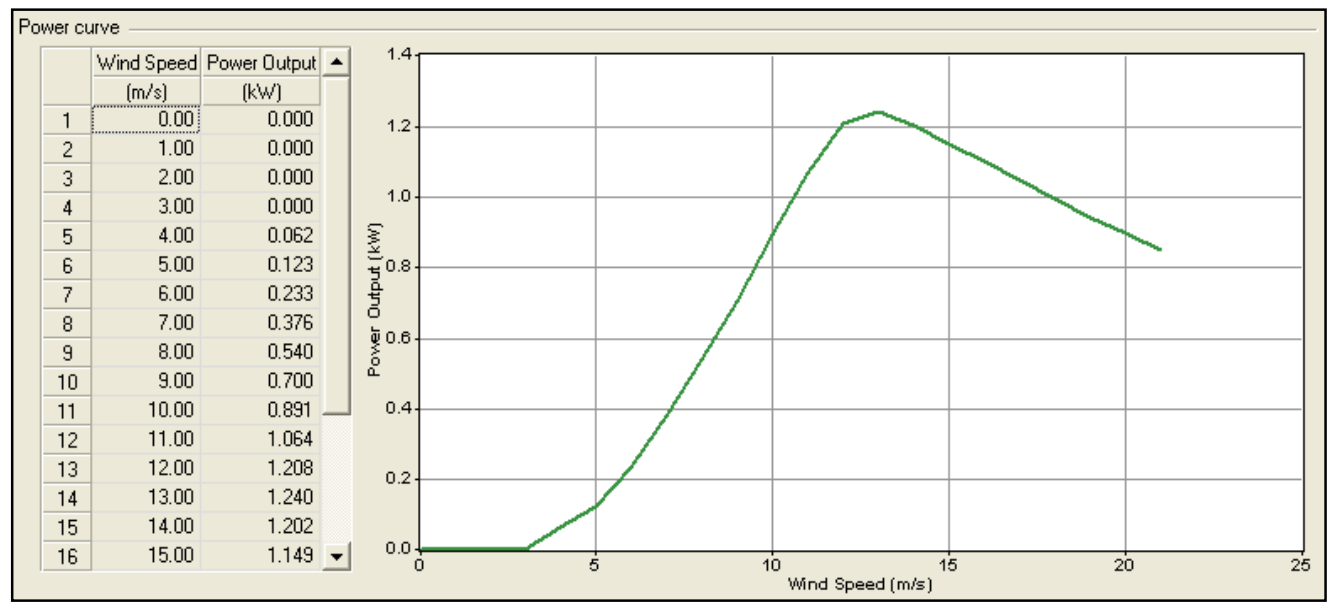

Figure 19. WT output power at different wind speed values.

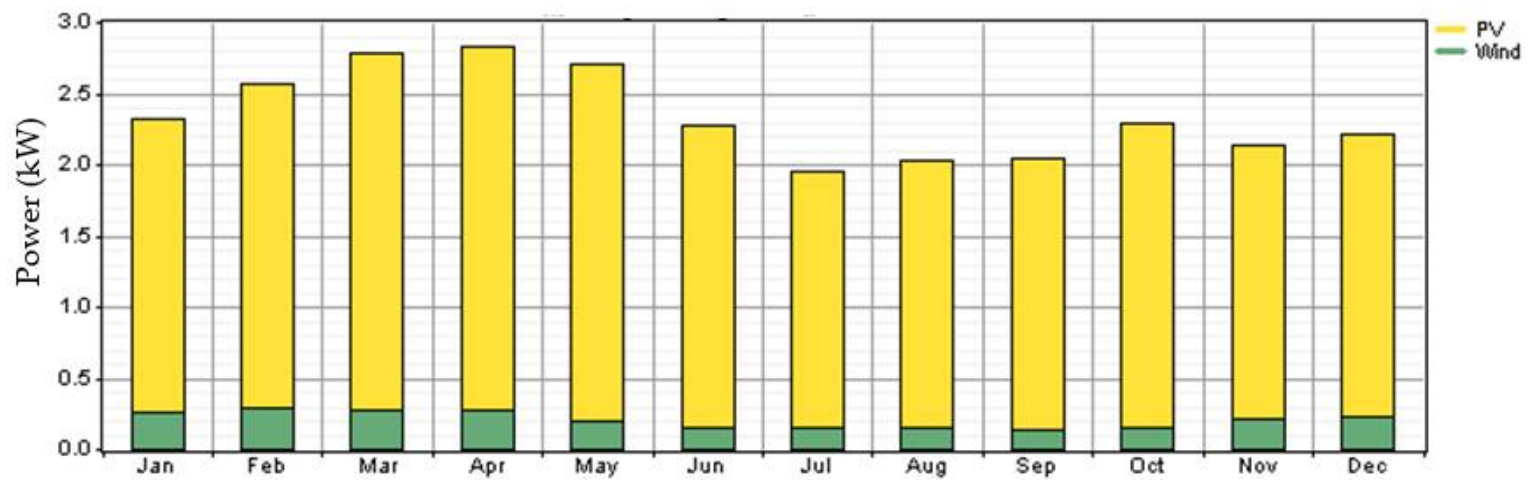

Figure 20. Monthly average electric production of the hybrid PV/WT system.

The total annual input energy of the Trojan L16P battery is $6957 \mathrm{kWh}$, whereas its total annual output energy is 5,939 $\mathrm{kWh}$. Thus, the total annual energy loss of the Trojan L16P battery is $1018 \mathrm{kWh}$. Furthermore, batteries can supply the UMTS-BS load autonomously for $72.6 \mathrm{~h}$, which was calculated using Equation (6). The expected lifetime of the battery is 10 years, as calculated using Equation (7). Figure 21 presents the monthly maximum and minimum SOCs of the Trojan L16P battery, which indicates that the DOD of this battery occurred at the end July and beginning of August. Additional details are provided in Figure 22, which shows a portion of the hourly simulation results of the energy content of the battery in a time series, in average hourly values of the PV array power output with SOC. The lowest level was reached on 4 August.

The total annual input energy of the inverter is $1301 \mathrm{kWh}$, whereas its total annual output energy is $1236 \mathrm{kWh}$. Thus, the total annual energy loss of the inverter is $65 \mathrm{kWh}$. Figure 23 presents the average monthly energy conversion of the inverter over 12 months.

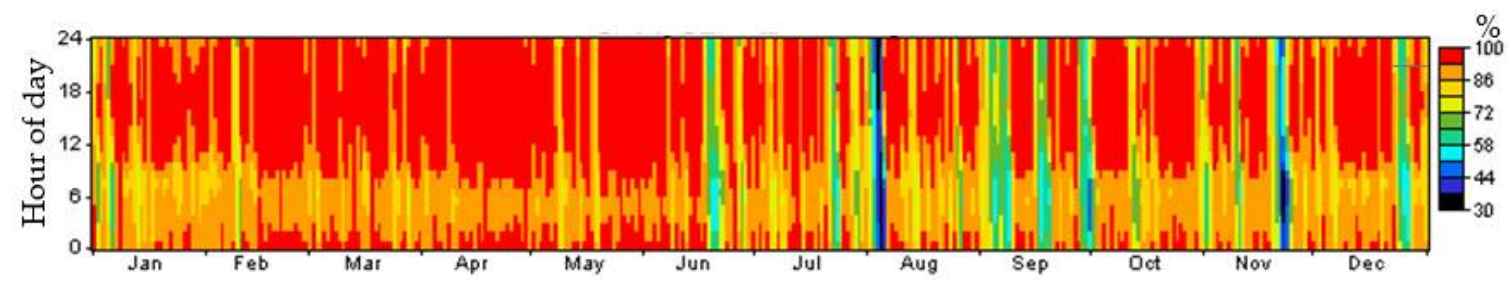

Figure 21. SOC of the battery in the hybrid PV/WT system. 


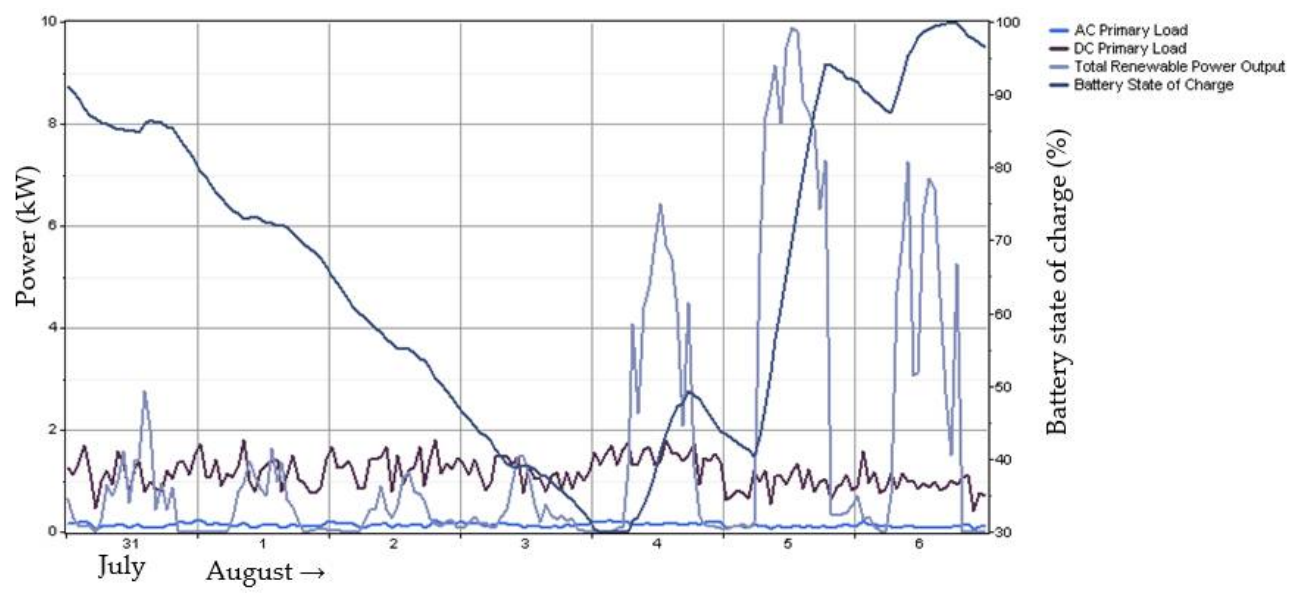

Figure 22. Hourly simulation results of the total renewable output power and energy stored in the battery bank.

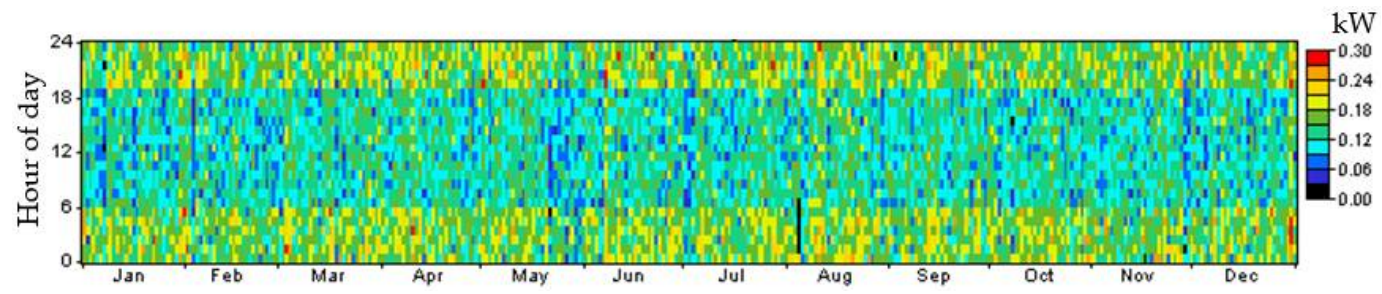

Figure 23. Inverter output power of the hybrid PV/WT system.

\subsubsection{Costs}

The cash flow summary for the hybrid PV/WT system within the project lifetime is presented in Figure 24 based on a solar radiation of $4.0 \mathrm{kWh} / \mathrm{m}^{2} /$ day and a wind speed of $4.0 \mathrm{~m} / \mathrm{s}$.

The hybrid PV /WT system has an IC of $\$ 28,420$, yearly O\&M cost of $\$ 778$, and salvage value of $\$ 5340$, which were calculated using Equation (11). No replacement cost is necessary because the project lifetime is 10 years, battery lifetime is estimated at 10 years, inverter and WT lifetimes are 15 years, and PV array lifetime is 25 years.

The total NPC throughout the project lifetime is $\$ 30,975$, which is calculated as follows: capital costs of $\$ 28,420+O \& M$ costs of $\$ 7270-$ salvage value of $\$ 4715=\$ 30,975$. Figure 25 summarizes the total discounted costs incurred within the project lifetime of the PV/WT hybrid system.

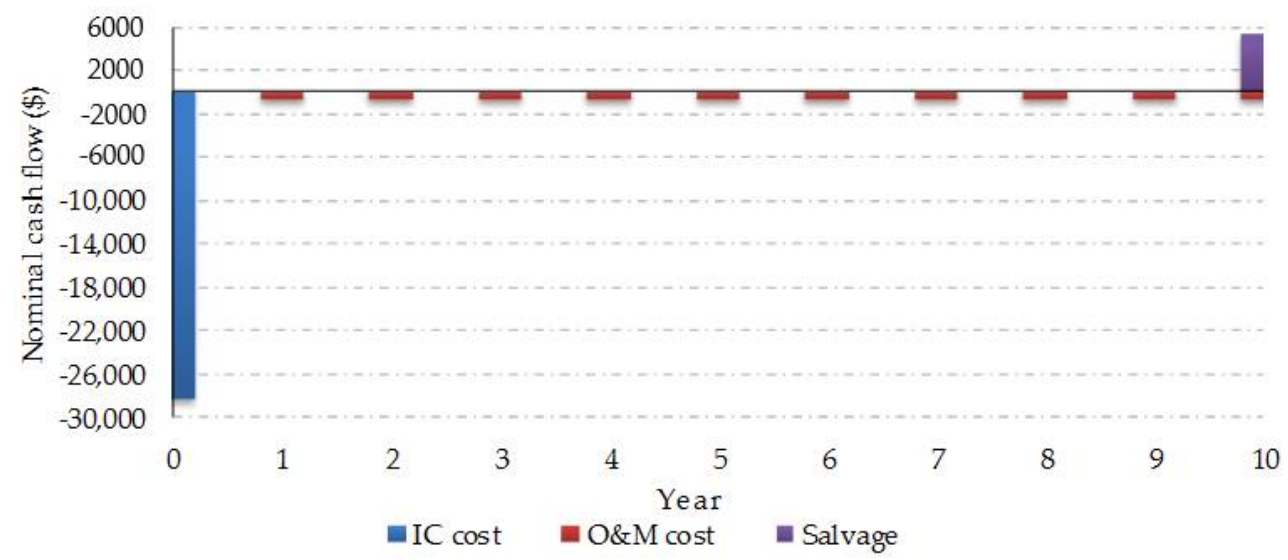

Figure 24. Summary of the cash flow of the hybrid PV/WT system throughout the project lifetime. 


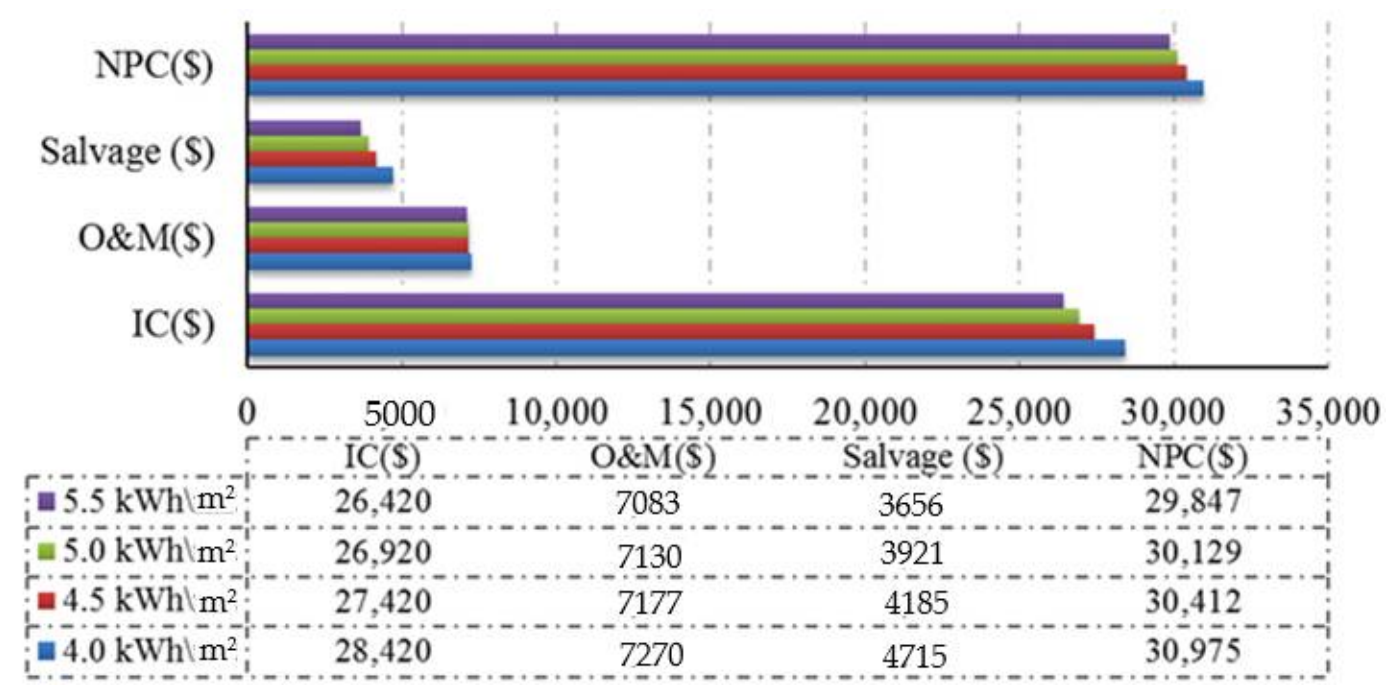

Figure 25. Summary of the total discounted costs throughout the project lifetime of the hybrid PV/WT system.

\section{Feasibility Comparison between the PV System and the Hybrid PV/WT System}

This section compares the two RESs used in this study. Comparison is performed in terms of energy and economics. This summary provides a clear basis for cellular network operators in selecting the best solution and ensuring sustainability through the improved planning of the cellular network.

\subsection{Energy Issue}

Figure 26 summarizes the annual energy contribution of the two proposed RESs. The annual energy required by the UMTS-BS load is $11,678 \mathrm{kWh}$; thus, both RESs can cover the load without shortage. However, the annual output energy of the hybrid PV/WT system is higher than that of the PV system by $8.12 \%$. In addition, the annual excess energy of the PV system reaches $13.78 \%$, whereas that of the hybrid PV/WT system reaches $21.51 \%$.

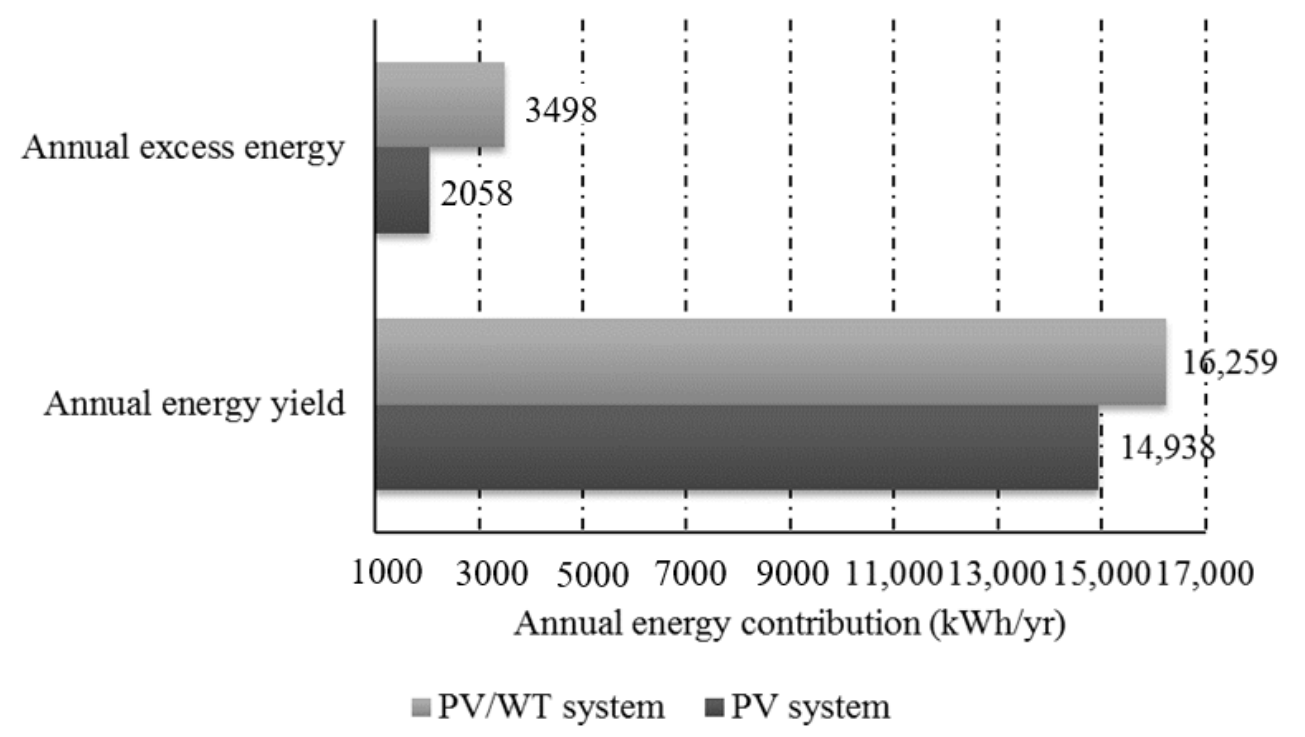

Figure 26. Comparison of the total yearly energy of the PV system vs. the hybrid PV/WT system. 


\subsection{Economic Issue}

Increasing profitability and reducing OPEX in a cellular network are important economic issues for cellular network operators. Figure 27 summarizes the total costs of the two proposed RESs. The NPC for the hybrid PV/WT system is higher than that for the PV system. This result is attributed to higher IC and O\&M costs for the hybrid PV/WT system. The salvage value for the hybrid PV/WT system is lower than that for the PV system because the former includes a new component (i.e., WT), which increases IC and O\&M costs.

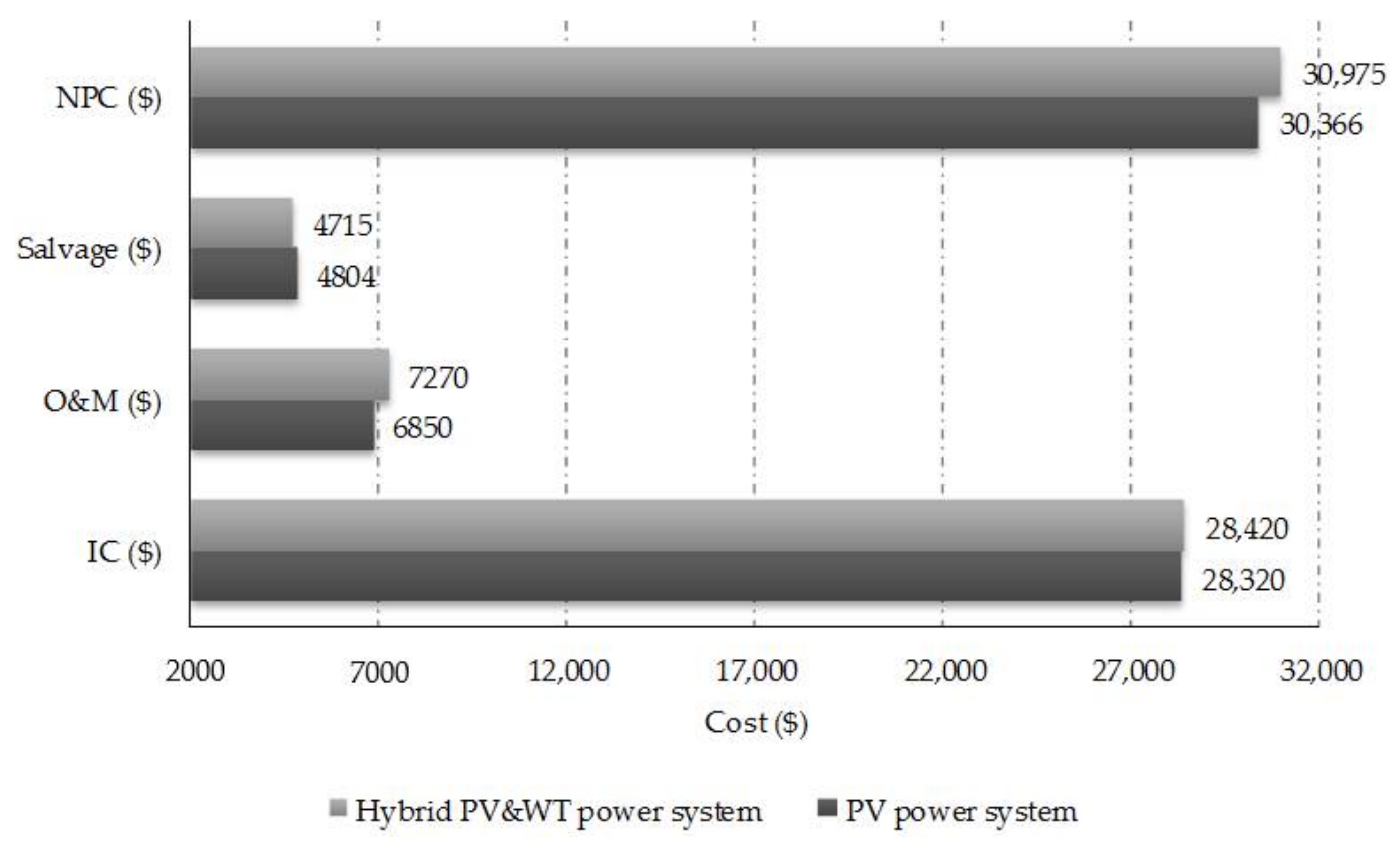

Figure 27. Comparison of the total costs for the PV system vs. the hybrid PV/WT system.

The preceding analysis indicates that the proposed PV system is an attractive solution for supplying energy to a remote UMTS-BS because this system provides increased levels of reliability and has low maintenance requirements.

\section{Feasibility Comparison between RESs and DG}

The required DG is approximately $5 \mathrm{~kW}$, which was computed as the maximum UMTS-BS, AC, and DC loads of $1.34 \mathrm{~kW}$ divided by DG efficiency of 30\% [20] $\times$ converter efficiency of $95 \%$. Comparison is performed in terms of economic feasibility and GHG emissions.

\subsection{PV System versus DG Solution}

\section{IC Cost}

(a) With the traditional power system (DG), UMTS-BS is fed only by DG. DG IC cost is obtained as follows: size $5 \mathrm{~kW} \times$ cost $\$ 660 / 1 \mathrm{~kW}[20]=\$ 3300$.

(b) With the proposed PV system, IC cost is $\$ 28,320$. IC cost for the PV system is considerably higher than that for the DG solution because the components of the PV system are costlier compared with those of the DG solution.

\section{Annual OEM Cost}

(a) DG: Total annual cost amounted to $\$ 5740$, which is broken down as follows: 
(ii) $\$ 5302$ for fuel cost at $\$ 1.04 / \mathrm{L}$ diesel price [23]

(b) PV system: Annual O\&M costs can be reduced to $\$ 733$, thereby yielding savings amounting to $87.23 \%$. However, the savings rate is expected to continue to increase with the continuous rise in fuel prices.

\section{$>$ Replacement Cost}

(a) DG: Mobile operators may be required to change DG every 3 years. Accordingly, the total DG replacement cost is $3 \times($ size $5 \mathrm{~kW} \times$ cost $\$ 660 / 1 \mathrm{~kW})$, with a total of at least $\$ 9900$.

(b) PV system: No replacement cost is necessary because the project lifetime is 10 years, whereas the PV array lifetime is 25 years.

\section{$>$ Salvage Value}

(a) DG: The salvage value for DG is frequently zero.

(b) PV system: The total salvage value is $\$ 5440$.

\section{$>$ NPC Cost}

(a) DG: NPC includes the IC of $\$ 3300+$ O\&M costs of $\$ 57,400+$ replacement costs of $\$ 9900=\$ 70,600$ throughout the project lifetime.

(b) PV system: NPC amounts to $\$ 30,366$. Hence, using the PV system can save up to $56.99 \%$. Figure 28 summarizes the OPEX of the DG compared with that of the proposed PV system.

\section{$>$ GHG Emissions}

The $\mathrm{CO}_{2}$ emission of diesel fuel is $2.68 \mathrm{~kg} / \mathrm{L}$ [24]. Hence, the total annual $\mathrm{CO}_{2}$ emission is $13,663 \mathrm{~kg}$, which was computed based on the specific annual diesel consumption of $5098 \mathrm{~L}$ multiplied by $2.68 \mathrm{~kg} \mathrm{CO}_{2} / \mathrm{L}$. Consequently, the trend toward RESs is increasing worldwide to eliminate GHG emissions, reduce costs, and protect the environment, given that RESs are considered green icons.

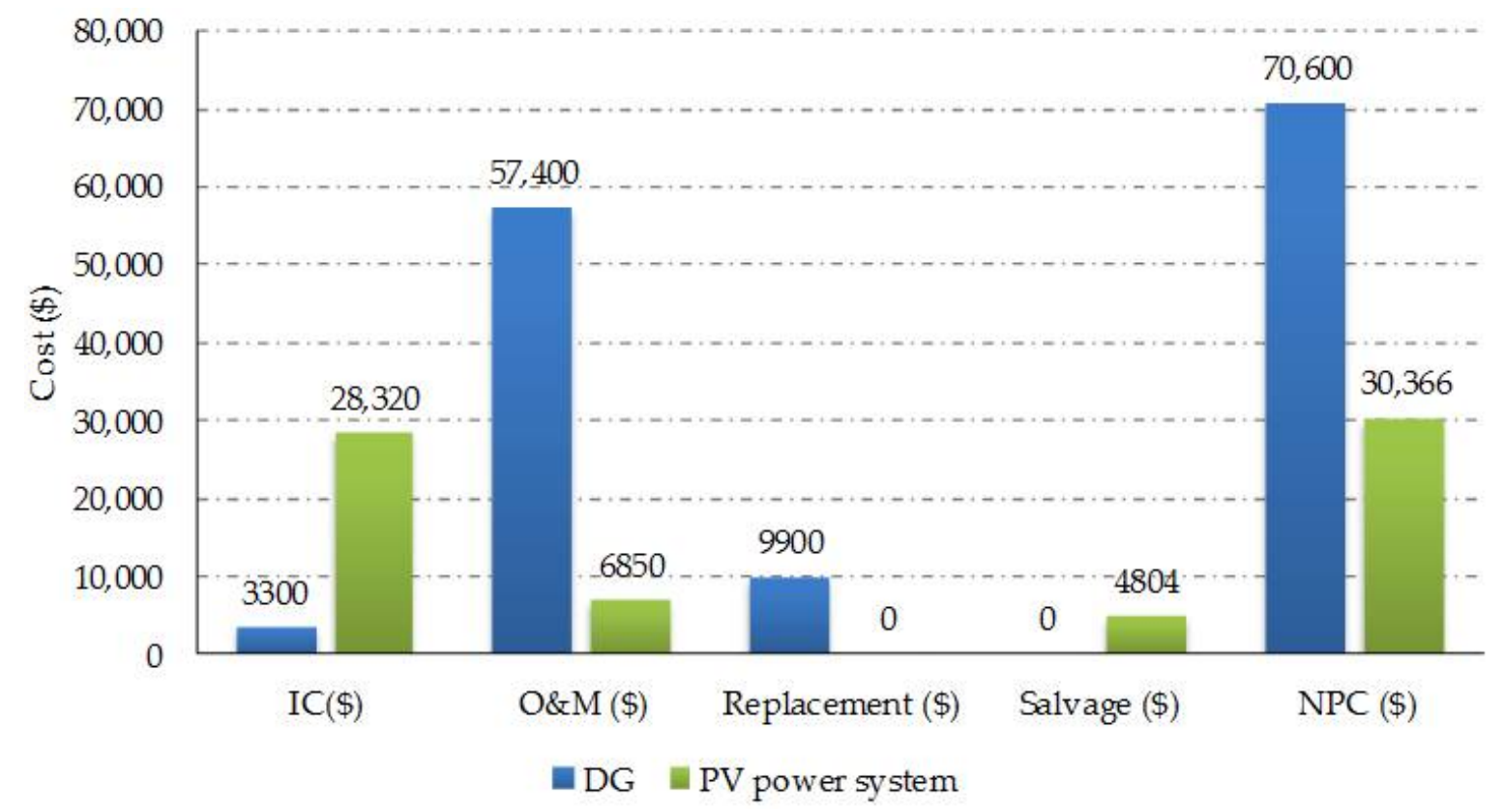

Figure 28. Comparison of the expenses of the PV system vs. DG throughout the project lifetime. 


\subsection{Hybrid PV/WT System versus DG Solution}

\section{$>$ IC Cost}

The IC cost of the hybrid PV/WT system is $\$ 28,420$.

\section{$>$ Annual OEM Cost}

The annual O\&M cost of the hybrid PV/WT system is $\$ 778$, thereby yielding savings amounting to $86.45 \%$ compared with DG.

\section{$>$ Replacement Cost}

No replacement cost is necessary because the project lifetime is 10 years, battery lifetime is estimated at 10 years, inverter and WT lifetimes are 15 years, and PV array lifetime is 25 years.

\section{$>$ Salvage Value}

The total salvage value is $\$ 5340$.

\section{$>$ NPC Cost}

NPC for the hybrid PV/WT system is $\$ 30,975$. Hence, using the hybrid PV/WT system can save up to $56.13 \%$ compared with DG. Figure 29 summarizes the OPEX of the DG compared with that of the proposed hybrid PV/WT system throughout the project lifetime.

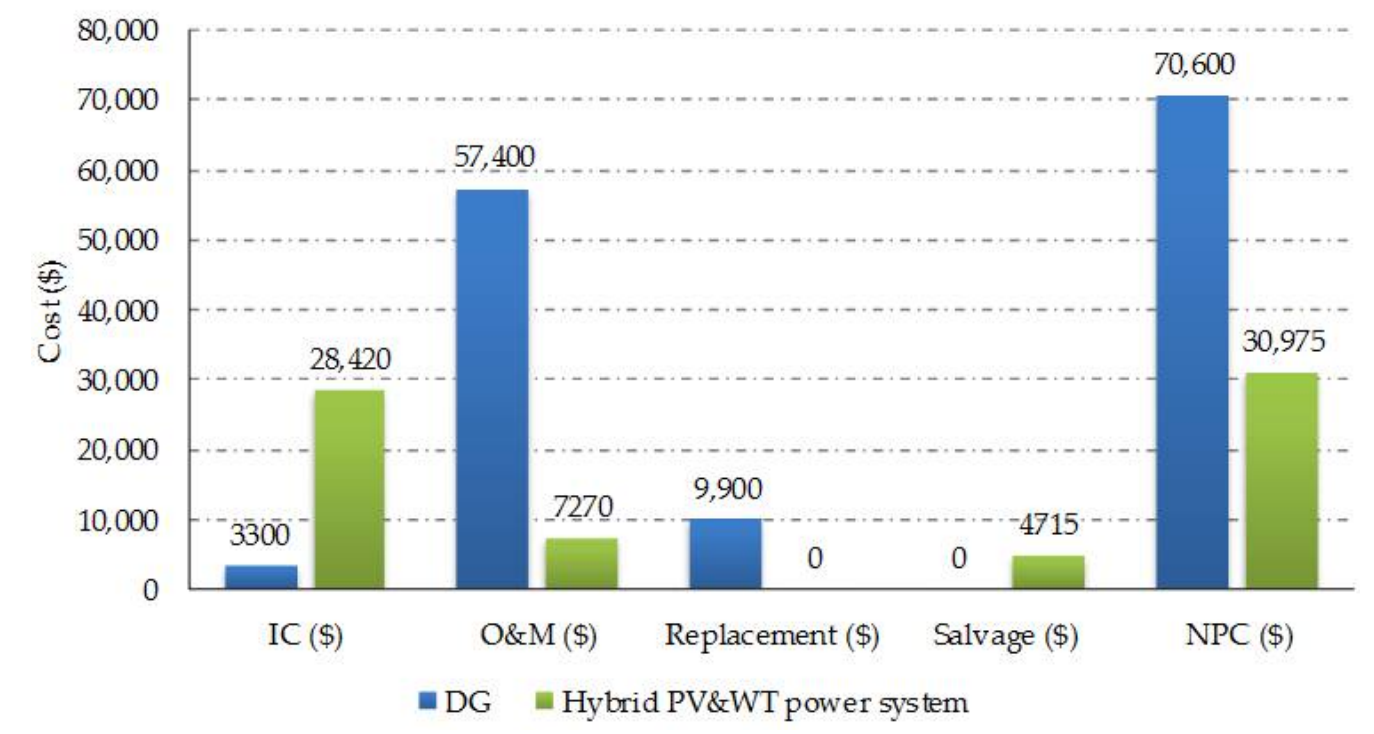

Figure 29. Comparison of the expenses of the hybrid PV/WT system vs. DG throughout the project lifetime.

\section{Conclusions and Recommendations}

A stand-alone PV system and a combined PV/WT system were studied. The annual energy output of the hybrid PV/WT system was higher than that of the stand-alone PV system. However, both systems covered the UMTS-BS load without shortage, and excess electricity can be stored in batteries for future use. In addition, NPC for the hybrid PV/WT system was also higher than that for the stand-alone PV system. The PV/WT system included an additional component (i.e., WT) that increased IC and O\&M costs, and consequently, total NPC. However, the total operating expenses that can be saved can reach $56.13 \%$ if a DG is replaced with the hybrid PV/WT energy system. Operating expense savings increased with the use of a stand-alone PV system by up to $56.99 \%$. These results indicate that a stand-alone PV system is more feasible for mobile network operators in terms of cost-effectiveness, 
sustainability, and clean energy. Therefore, the current arrangement of diesel-powered UMTS-BS can be replaced with a stand-alone PV system, which can provide the following advantages:

- A nonconventional energy PV power system is found to be technically feasible, emission-less, and cost-effective in the long run.

- The environment-friendly nature of this system makes it an attractive option for supplementing energy supply in rural areas.

- $\quad$ Load is optimally satisfied.

- Accelerated deployment of UMTS-BSs in remote and rural locations can be achieved.

- Expanded coverage of mobile networks can be realized to provide service to the largest number of users who will benefit from the transition from physical to mobile operators.

In this study, the opportunities and prospects of the economic and environmental impacts of the deployment of RES-powered cellular BSs was extensively reviewed. This study focused on the case of South Korea, which has an average solar radiation of $4.0 \mathrm{kWh} / \mathrm{m}^{2} /$ day and wind speed of $4.0 \mathrm{~m} / \mathrm{s}$. Nevertheless, the study can be extended to include neighboring countries with slight differences in daily peak sunlight hours, solar resources, and economic factors. In general, the mid-latitude region located between $30^{\circ} \mathrm{N}$ and $30^{\circ} \mathrm{S}$ latitudes is a preferred region for solar-powered BSs. The average irradiance in this region, except for the inland areas of China, ranges from $4.5 \mathrm{kWh} / \mathrm{m}^{2}$ to $7.5 \mathrm{kWh} / \mathrm{m}^{2}$. Potential locations for wind-powered BSs are widely distributed in mountainous regions and coastal areas. However, the number of such locations may be further reduced considering the desolate conditions of mountainous regions. In accordance with these requirements, wind-powered BSs may be established in the northeastern coast of North America, the southern area of South America, England, the northern region of Europe, the northwestern part of India, the southern coast of China, and the coastal areas of Japan.

Author Contributions: As the first author, M.H.A. wrote the main parts and the first draft of this paper. J.H.K. conducted a study on the case study, and wrote Section 2. J.K. revised the final version of paper.

Acknowledgments: This work was supported by the Human Resources Development of the Korea Institute of Energy Technology Evaluation and Planning (KETEP) grant funded by the Korea government Ministry of Trade, industry and Energy (No. 20164030201340).

Conflicts of Interest: The authors declare no conflict of interest.

\section{References}

1. Alsharif, M.H.; Kim, J.; Kim, J.H. Green and Sustainable Cellular Base Stations: An Overview and Future Research Directions. Energies 2017, 10, 587. [CrossRef]

2. Hasan, Z.; Boostanimehr, H.; Bhargava, V.K. Green Cellular Networks: A Survey, Some Research Issues and Challenges. IEEE Commun. Surv. Tutor. 2011, 13, 524-540. [CrossRef]

3. Asif, M.; Muneer, T. Energy supply, its demand and security issues for developed and emerging economies. Renew. Sustain. Energy Rev. 2007, 11, 1388-1413. [CrossRef]

4. Aris, A.M.; Shabani, B. Sustainable power supply solutions for off-grid base stations. Energies 2015, 8, 10904-10941. [CrossRef]

5. Nematollahi, O.; Kim, K.C. A feasibility study of solar energy in South Korea. Renew. Sustain. Energy Rev. 2017, 77, 566-579. [CrossRef]

6. Alsharif, M.H.; Kim, J. Hybrid Off-Grid SPV/WTG Power System for Remote Cellular Base Stations Towards Green and Sustainable Cellular Networks in South Korea. Energies 2017, 10, 9. [CrossRef]

7. Borhanazad, H.; Mekhilef, S.; Saidur, R.; Boroumandjazi, G. Potential application of renewable energy for rural electrification in Malaysia. Renew. Energy 2013, 59, 210-219. [CrossRef]

8. Alsharif, M.H.; Kim, J. Optimal Solar Power System for Remote Telecommunication Base Stations: A Case Study Based on the Characteristics of South Korea's Solar Radiation Exposure. Sustainability 2016, 8, 942. [CrossRef]

9. Koo, C.; Hong, T.; Lee, M.; Park, H.S. Estimation of the Monthly Average Daily Solar Radiation using Geographic Information System and Advanced Case-Based Reasoning. Environ. Sci. Technol. 2013, 47, 4829-4839. [CrossRef] [PubMed] 
10. KMA. Annual Climatological Report 2013. Korea Meteorological Administration. 2013. Available online: http:/ / www.kma.go.kr/weather/observation/data_monthly.jsp (accessed on 22 May 2018).

11. National Institute of Meteorological Sciences (NIMS). Wind Weather Map. Available online: http:/ / www. greenmap.go.kr/02_data/data01.do\#2\#1\#1 (accessed on 22 May 2018).

12. Baek, S.; Kim, H.; Chang, H.J. Optimal hybrid renewable power system for an emerging island of South Korea: The case of Yeongjong Island. Sustainability 2015, 7, 13985-14001. [CrossRef]

13. Schmitt, G. The Green Base Station. In Proceedings of the 4th International Conference on Telecommunication Energy Special Conference (TELESCON), Vienna, Austria, 10-13 May 2009; pp. 1-6.

14. Imran, M.; Katranaras, E.; Auer, G.; Blume, O.; Giannini, V.; Godor, I.; Jading, Y.; Olsson, M.; Sabella, D.; Skillermark, P. Energy Efficiency Analysis of the Reference Systems, Areas of Improvements and Target Breakdown; Technical Report ICT-EARTH Deliverable D2.3; Centre for Communication Systems Research: Guildford, UK, 2011.

15. Arnold, O.; Richter, F.; Fettweis, G.; Blume, O. Power Consumption Modeling of Different Base Station Types in Heterogeneous Cellular Networks. In Proceedings of the 2010 IEEE International Conference on Future Network and Mobile Summit, Florence, Italy, 16-18 June 2010; pp. 1-8.

16. Timilsina, G.R.; Kurdgelashvili, L.; Narbel, P.A. Solar energy: Markets, economics and policies. Renew. Sustain. Energy Rev. 2012, 16, 449-465. [CrossRef]

17. Sindhu, S.; Nehra, V.; Luthra, S. Solar energy deployment for sustainable future of India: Hybrid SWOC-AHP analysis. Renew. Sustain. Energy Rev. 2017, 72, 1138-1151. [CrossRef]

18. Alsharif, M.H. A solar energy solution for sustainable third generation mobile networks. Energies 2017, 10, 429. [CrossRef]

19. Kumar, B.S.; Sudhakar, K. Performance evaluation of $10 \mathrm{MW}$ grid connected solar photovoltaic power plant in India. Energy Rep. 2015, 1, 184-192. [CrossRef]

20. Kusakana, K.; Vermaak, H.J. Hybrid Renewable Power Systems for Mobile Telephony Base Stations in Developing Countries. Renew. Energy 2013, 51, 419-425. [CrossRef]

21. Ahmed, A.S. Wind energy as a potential generation source at Ras Benas, Egypt. Renew. Sustain. Energy Rev. 2010, 14, 2167-2173. [CrossRef]

22. Lambert, T.; Gilman, P.; Lilienthal, P. Micropower System Modeling with Homer. 2006. Available online: http: / / homerenergy.com/documents/MicropowerSystemModelingWithHOMER.pdf (accessed on 22 May 2018).

23. Global Petrol Prices. Available online: http://www.globalpetrolprices.com/South-Korea/diesel_prices/ (accessed on 22 May 2018).

24. Calculation of $\mathrm{CO}_{2}$ Emissions. Available online: http://people.exeter.ac.uk/TWDavies/energy_conversion/ Calculation \%20of\%20CO2\%20emissions\%20from\%20fuels.htm (accessed on 22 May 2018). 